\title{
Método para aplicação do trabalho padronizado
}

\author{
Method for the application of standardized work in \\ construction
}

\section{Renato Nunes Mariz \\ Flávio Augusto Picchi}

\section{Resumo

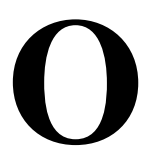

trabalho padronizado tem sido amplamente utilizado na manufatura. Através de sua aplicação, resultados positivos em termos de produtividade e estabilização de processos tem alcançados. $\mathrm{Na}$ construção, a adoção desta forma de padronização é ainda incipiente, sendo observadas apenas aplicações parciais. Como consequência, não existe ainda conhecimento suficiente sobre as formas eficazes de adaptação deste conceito ao contexto da construção, com resultados tão significativos quanto os observados na manufatura. O objetivo deste artigo é propor um método para aplicação do trabalho padronizado ao contexto da construção. Foram realizados dois estudos de caso exploratórios em atividades de características diferentes: assentamento de porcelanato no piso e execução de estaca Franki. O método proposto consiste em uma adaptação de outro método de aplicação do trabalho padronizado, que vem sendo utilizado na manufatura. Constatou-se, ao final da pesquisa, que este método pode ser adaptado ao setor da construção, possibilitando uma análise estruturada com foco na otimização de recursos utilizados. A principal contribuição do trabalho é evidenciar a potencialidade de aplicação do trabalho padronizado no contexto da construção e despertar o interesse na aplicação prática deste conceito, e na continuidade de pesquisas neste tópico.

Palavras-chave: Trabalho padronizado. Lean thinking. Padrinização. Gestão da produção.

\begin{abstract}
Standardized work has been widely used in manufacturing. Its application has brought positive results in terms of productivity and process stability. In construction, the adoption of this type of standardization is still incipient, and most applications so far are partial. Consequently, there is not enough knowledge about effective ways of adapting this concept into the construction context, which could bring significant results, as observed in manufacturing. The aim of this paper is to propose a method to apply standardize work in the construction context. Two exploratory case studies were conducted, in different types of activities: ceramic floor tiles and Franki piles execution. The proposed method is an adaptation of an existing method for applying standardized that has been used in manufacturing. construction context, providing a structured analysis focused on resources optimization. The study main contribution is to provide evidence on the applicability of standardized work in the construction industry, encouraging the practical application of this concept, and further research studies on this topic.

Keywords: Standardized work. Lean thinking. Standardization. Production management.
\end{abstract}

Flávio Augusto Picchi Universidade Estadual de Campinas Lean Institute Brasil São Paulo - SP - Brasil

Recebido em 28/11/11 Aceito em 13/08/13

MARIZ, R. N.; PICCHI, F. A. Método para aplicação do trabalho padronizado. Ambiente Construído, Porto Alegre, v. 7 13, n. 3, p. 7-27, jul./set. 2013.

ISSN 1678-8621 Associação Nacional de Tecnologia do Ambiente Construído. 


\section{Introdução}

A indústria da construção tem sido pressionada a melhorar as práticas do gerenciamento da produção devido a alguns fatores, como baixa produtividade, alto índice de desperdício, demanda social por moradia (em alguns países como o Brasil) e imagem negativa em comparação com outros setores industriais (SANTOS, 1999).

Uma filosofia que pode trazer contribuições nesse contexto é o Lean Thinking. Baseada na generalização dos preceitos do Sistema Toyota de Produção, é aplicável aos mais diversos setores industriais e de serviços. Tem como base a eliminação de desperdício ao longo do fluxo de valor, desse modo encurtando prazos (lead times), reduzindo custos e também aumentando a qualidade do produto (WOMACK; JONES, 1998).

O Lean Thinking tem sido disseminado na manufatura e mais recentemente na construção civil, na qual as oportunidades para suas aplicações são inúmeras (PICCHI, 2003).

Desde a proposição pioneira de Womack e Jones (1998) quanto aos cinco princípios do Lean Thinking (valor, fluxo de valor, fluxo contínuo, produção puxada e perfeição), o princípio de fluxo contínuo tem tido sua importância destacada nessa filosofia. Para a operacionalização desse princípio, um elemento que tem sido amplamente utilizado é o trabalho padronizado (ROTHER; HARRIS, 2002).

O trabalho padronizado reduz desperdícios, diminui a carga de trabalho e riscos de acidentes, e aumenta a produtividade e a satisfação dos trabalhadores (KISHIDA; SILVA; GUERRA, 2006; WHITMORE, 2008). Shook (1997) relata que o Sistema Toyota de Produção busca trabalhar com alta qualidade, baixo custo, baixo tempo de resposta ao cliente, flexibilidade de volume e mix para atender à demanda. Segundo o mesmo autor, a base para esses resultados é o trabalho padronizado.

Já no contexto da construção, as aplicações do trabalho padronizado são ainda embrionárias, com poucos trabalhos, entre os quais Francelino et al. (2006), Saffaro (2007), Gallardo (2007), Feng e Ballard (2008), Bulhões (2009) e Fazinga e Saffaro (2012). Essas pesquisas abordam aplicações de elementos que constituem o trabalho padronizado, não abordando as atividades e movimentos dos operários de forma individual, foco do trabalho padronizado em suas aplicações na manufatura e deste artigo. Não se encontram também na literatura discussões sobre métodos de aplicação do trabalho padronizado na construção que facilitem sua disseminação, como existe, por exemplo, na manufatura.

Com base nessas considerações, o objetivo deste artigo é adaptar o método para aplicação do trabalho padronizado na manufatura para o contexto da construção.

\section{Trabalho padronizado}

O trabalho padronizado, como entendido dentro da filosofia Lean Thinking, tem suas raízes históricas no Training Within Industry (TWI), programa de treinamento de mão de obra desenvolvido nos Estados Unidos durante a Segunda Guerra Mundial com o intuito de suprir a carência de mão de obra qualificada (HUNTZINGE, 2005). O TWI foi disseminado no Japão após a Segunda Guerra Mundial, juntamente com os programas da qualidade. O programa de instruções de trabalho (job instructions) do TWI incorporou-se às práticas da Toyota, que deram origem ao conceito de trabalho padronizado hoje usado no Lean Thinking (SMALLEY, 2005; LIKER; MEIER, 2007).

As definições de diversos autores para o trabalho padronizado (TP) (Quadro 1) convergem para a identificação de três elementos: takt time, sequência e estoque padrão.

Neste trabalho é adotada a definição proposta pelo Lean Institute Brasil (2003, p. 82):

\section{$O$ trabalho padronizado estabelece procedimentos precisos para o trabalho de cada um dos operadores em um processo de produção, baseado em três elementos: tempo takt, sequência e estoque padrão.}

$\mathrm{O}$ aspecto de estabelecer procedimentos para cada operador diferencia o trabalho padronizado (focado nos movimentos do operador) das instruções de trabalho ou outras formas tradicionais de padronização, focadas no processo ou etapas que o produto passa (LIKER; MEIER, 2007). 
Quadro 1 - Definições para trabalho padronizado

\begin{tabular}{|l|l|}
\hline \multicolumn{1}{|c|}{ Referência } & \multicolumn{1}{c|}{ Definição } \\
\hline Cudney (2001) & $\begin{array}{l}\text { É uma ferramenta para determinar o máximo desempenho com o mínimo de } \\
\text { desperdício por meio de uma melhor combinação das operações que } \\
\text { envolvem homem e máquina. Seu principal objetivo é a melhoria nos } \\
\text { processos. }\end{array}$ \\
\hline Fujimoto (1999) & $\begin{array}{l}\text { Padronização de todas as formas de realizar atividades em todos os processos } \\
\text { da empresa. }\end{array}$ \\
\hline $\begin{array}{l}\text { Kishida, Silva e Guerra } \\
\text { (2006) }\end{array}$ & $\begin{array}{l}\text { Trabalho Padronizado (TP) é uma ferramenta lean básica centrada no } \\
\text { movimento e trabalho do operador e aplicada em situações de processos } \\
\text { repetitivos, visando à eliminação de desperdícios. O TP baseia-se em três } \\
\text { elementos: takt time, sequência e estoque padrão em processo. }\end{array}$ \\
\hline $\begin{array}{l}\text { Lean Institute Brasil } \\
\text { (2003) }\end{array}$ & $\begin{array}{l}\text { Estabelecimento de procedimentos precisos para o trabalho de cada um dos } \\
\text { operadores em um processo de produção, baseado em três elementos: takt } \\
\text { time, sequência e estoque padrão. }\end{array}$ \\
\hline Liker e Meier (2007) & Método de trabalho geral definido observando-se as perdas. \\
\hline $\begin{array}{l}\text { Narusawa e Shook } \\
(2009)\end{array}$ & $\begin{array}{l}\text { Determinação de procedimentos exatos para o trabalho de cada operador, } \\
\text { baseado em três elementos: takt time, sequência e estoque padrão. }\end{array}$ \\
\hline $\begin{array}{l}\text { Marksberry, Rammohan } \\
\text { e Vu (2011) }\end{array}$ & $\begin{array}{l}\text { Não é somente uma ferramenta de documentação ou treinamento, mas sim } \\
\text { uma ferramenta de análise de trabalho. }\end{array}$ \\
\hline Ohno (1997) & $\begin{array}{l}\text { Definição clara e concisa do trabalho, através das folhas de trabalho padrão, } \\
\text { baseado em três elementos: tempo de ciclo (takt time), sequência e inventário } \\
\text { padrão. }\end{array}$ \\
\hline Spear e Bowen (1999) & $\begin{array}{l}\text { Definição minuciosa do trabalho de cada trabalhador, em termos de } \\
\text { conteúdo, sequência, tempo e resultado. }\end{array}$ \\
\hline
\end{tabular}

Os três elementos do TP são descritos a seguir:

(a) tempo takt: é a velocidade com a qual os clientes solicitam os produtos acabados, sendo esta determinada pela divisão do tempo total disponível de produção por turno pela demanda do cliente (ROTHER; HARRIS, 2002);

(b) sequência: a ordem das ações que cada trabalhador deve desempenhar dentro do tempo takt (MONDEM, 1998); e

(c) estoque padrão em processo: é a quantidade mínima de estoque necessária para manter a continuidade no fluxo de produção (OHNO, 1997).

Segundo o Lean Institute Brasil (2003), três documentos básicos são comumente utilizados na criação do trabalho padronizado: Folha de Capacidade de Produção (FCP), Diagrama de Trabalho Padronizado (DTP) e Tabela de Combinação de Trabalho Padronizado (TCTP). Esses documentos são utilizados pelos engenheiros e supervisores para projetar o processo, e pelos operadores, para fazer melhorias em suas próprias tarefas.

Alguns autores, como Narusawa e Shook (2009), Rother e Harris (2002) e Marksberry, Rammohan e $\mathrm{Vu}$ (2011), mencionam documentos auxiliares, como a Folha de Estudo de Processo (FEP) e o
Gráfico de Balanceamento do Operador (GBO) como fundamentais para o estabelecimento do trabalho padronizado. A FEP é utilizada para coleta de dados, e o GBO é utilizado para analisar os dados coletados pela FEP. Alukal e Manos (2006) também relatam que o diagrama de espaguete é útil para deixar aparentes os desperdícios relativos a deslocamento e transporte realizados pelos funcionários. Seguem abaixo as definições destes documentos.

(a) Folha de Capacidade de Produção (FCP) é um formulário que determina a capacidade de produção de cada máquina utilizada em determinado processo, levando em consideração fatores tais como o tempo manual da operação, o tempo de ciclo das máquinas e set up (MONDEM, 1998);

(b) Diagrama de Trabalho Padronizado (DTP) ilustra o deslocamento dos funcionários na área de trabalho através de um leiaute (LEAN..., 2003). Sua função é auxiliar o trabalhador sobre como ele deve executar seu trabalho em relação à sequência do trabalho e à localização do estoque (LIKER; MEIER, 2007);

(c) Tabela de Combinação do Trabalho Padronizado (TCTP) é uma tabela que apresenta a combinação do tempo de trabalho manual e o 
tempo da caminhada de cada trabalhador com o tempo de processamento da máquina (LEAN..., 2003), ou seja, a tabela completa mostra as interações entre operadores e máquinas no processo analisado e permite que se recalcule o conteúdo de trabalho dos operadores, conforme o tempo takt expande-se ou contrai-se;

(d) a Folha de Estudo de Processo (FEP) é uma planilha que auxilia a coleta de tempos de um processo, mediante a identificação e a cronometragem de cada elemento de trabalho (LUYSTER, 2006). Um elemento de trabalho pode ser definido com "o menor incremento de trabalho que pode ser transferido a outra pessoa" (ROTHER; HARRIS, 2002);

(e) o Gráfico de Balanceamento do Operador (GBO) é um quadro onde está descrita a distribuição da carga de trabalho entre os operadores em relação ao tempo takt, baseado em dados reais observados e registrados pela FEP (ROTHER; HARRIS, 2002); e

(f) diagrama de espaguete é uma ferramenta que mostra o deslocamento de um produto ou o deslocamento de um operador (WOMACK; JONES, 1998). Essa ferramenta serve para ilustrar os desperdícios relativos ao deslocamento dos funcionários.

Os documentos são utilizados de modo combinado, para que se possa alcançar resultados significativos (MARKSBERRY; RAMMOHAN; VU, 2011). O Quadro 2 mostra as relações desses documentos com os elementos do TP.

Rother e Harris (2002), ao discutir a criação de fluxo contínuo, apresentam um guia prático, que resulta no estabelecimento de trabalho padronizado, que pode ser considerado como um método para aplicação do TP, utilizado na manufatura. Esse método baseia-se em onze perguntas e mais dois passos de implantação, que auxiliam na identificação de desperdícios no nível de movimentos do operador e planejamento de sua eliminação, consolidado a melhoria através do TP resultante. Esse método serviu de base para a proposta apresentada neste artigo, sendo seus itens discutidos adiante.

\section{Método da pesquisa}

A estratégia adotada nesta pesquisa foi a de estudos de caso exploratórios. O delineamento da pesquisa estabeleceu as seguintes etapas:

(a) levantamento em literatura de método utilizado para aplicação do trabalho padronizado. Este estudo levou à escolha do método descrito por Rother e Harris (2002) como um referência disseminada na manufatura;

(b) adaptação deste método, considerando características da construção;

(c) aplicação deste método em dois estudos de caso, com diferentes características;

(d) discussão da aplicabilidade do método e utilidade nestes contextos e dos resultados potenciais apontados; $\mathrm{e}$

(e) proposição de um método para aplicação do trabalho padronizado na construção, baseado nestas observações.

Para os estudos de caso, escolheram-se uma atividade com importante componente de trabalho manual (Caso 1) e outra com utilização intensiva de equipamentos, em que também houve a oportunidade de se aplicar o estudo a mais de um operador (Caso 2).

As fontes de evidências utilizadas nesses estudos foram documentos fornecidos pelas empresas, entrevistas com funcionários e visitas in loco. Seguem informações sobre estes casos e respectivos procedimentos de coleta de dados adotados.

\section{Quadro 2 - Relação entre documentos e elementos do trabalho padronizado}

\begin{tabular}{|l|c|c|c|}
\hline \multicolumn{1}{|c|}{$\begin{array}{c}\text { Principais documentos do trabalho } \\
\text { padronizado }\end{array}$} & \multicolumn{3}{c|}{ Elementos do trabalho padronizado } \\
\cline { 2 - 4 } & Tempo takt & Sequência & $\begin{array}{c}\text { Estoque padrão em } \\
\text { processo }\end{array}$ \\
\hline Folha de capacidade de produção & $\mathrm{x}$ & & \\
\hline $\begin{array}{l}\text { Tabela de combinação do trabalho } \\
\text { padronizado }\end{array}$ & $\mathrm{x}$ & $\mathrm{x}$ & \\
\hline Diagrama de trabalho padronizado & & $\mathrm{x}$ & $\mathrm{x}$ \\
\hline Folha de estudo de processo & & $\mathrm{x}$ & \\
\hline Gráfico de balanceamento do operador & $\mathrm{x}$ & $\mathrm{x}$ & \\
\hline Diagrama de espaguete & & $\mathrm{x}$ & \\
\hline
\end{tabular}

10 Mariz, R. N.; Picchi, F. A. 


\section{Caso 1}

A atividade escolhida foi a execução de porcelanato. Essa tarefa foi realizada por uma empresa especializada em serviços de acabamento. A obra na qual foi realizado este estudo foi um edifício residencial na cidade de Belém, PA, de vinte e dois pavimentos. Foram cronometradas as atividades do pedreiro assentador do porcelanato no piso, primeiro durante um turno todo de trabalho, e depois foi feito vídeo do assentamento de dez peças de porcelanato, a partir do qual foi cronometrado o ciclo repetitivo, registrando-se na folha de estudo de processo. Procedeu-se então à análise através do método adaptado, utilizando-se em cada passo os documentos aplicáveis, entre os quais:

(a) folha de estudo de processos gráfico de balanceamento do operador;

(b) diagrama de trabalho padronizado;

(c) tabela combinada do trabalho padronizado; $\mathrm{e}$

(d) diagrama de espaguete.

\section{Caso 2}

A obra escolhida foi um edifício residencial na cidade de Campinas, SP, de três torres de quatro pavimentos cada, executada por empresa construtora e incorporadora de atuação nacional. A atividade na qual este estudo foi desenvolvido foi a execução de estacas Franki. Preliminarmente foi realizada uma entrevista com o engenheiro responsável pela obra para coleta de informações sobre a forma e tempo de realização das atividades e distribuição dos equipamentos. Seguiu-se de coleta de dados com cronometragem direta de diferentes operadores e filmagem do serviço de concretagem em diversos ciclos. O registro e a análise seguiram os passos do método adaptado e uso de documentos, da mesma forma que descrito para o Caso 1, sendo neste caso, adicionalmente, utilizada a folha de capacidade de processos para análise dos equipamentos empregados.

Como um estudo exploratório, diversas são as limitações da pesquisa, entre as quais podemos citar: o número reduzido de estudos de caso (2); a construção civil apresentar diferentes situações, nas quais o método deve ser posteriormente testado. Os estudos de caso abrangeram um número limitado de operadores e de atividades relacionadas; o Caso 1, por exemplo, analisou somente o assentador de porcelanato, e não seu ajudante; o Caso 2 analisou as operações de produção de concreto, e não a cravação da estaca em si; quanto maior a abrangência de estudos futuros, maior é o potencial de o método apontar formas de obter ganhos. O método foi aplicado parcialmente, faltando estudos da implementação do TP gerado e análise de resultados obtidos após aplicações das proposições geradas.

\section{Adaptação de método para aplicação do TP na manufatura para o contexto da construção}

Para nortear este estudo, usou-se como ponto de partida o método proposto por Rother e Harris (2002) para a manufatura, adaptando-se suas perguntas e passos para o contexto da construção. Buscou-se manter o máximo possível a mesma linha e raciocínio do método de Rother e Harris (2002), com adaptações de forma, de tal modo a facilitar sua compreensão no contexto da construção. Foram também inseridas pequenas adaptações de conteúdo, considerando situações específicas da construção discutidas adiante. Buscou-se, ainda, incorporar ao título de cada etapa indicações de ações pertinentes em cada uma. Seguem comentários sobre as adaptações propostas (Quadro 3).

Na questão A, Rother e Harris (2002) discutem a seleção da família de produtos de forma que o trabalho padronizado gerado tenha flexibilidade suficiente para adaptar-se às mudanças de demanda. No caso da construção, a escolha recai numa atividade, ou conjunto de atividades dentro de uma obra. O trabalho padronizado aplica-se a atividades repetitivas, sendo recomendado que elas tenham estabilidade básica nos 4Ms: mão de obra, materiais, máquinas e método (ROTHER; HARRIS, 2002). O método pode ser entendido num sentido amplo, abrangendo o próprio TP, bem como planejamento, projeto, segurança, etc.

A questão B foi mantida na etapa 2, observando-se que na construção o tempo takt deve ser calculado considerando-se o cronograma da obra, conforme já discutido por outros autores (BULHÕES, 2009). 
Quadro 3 - Adaptação das perguntas e passos do TP da manufatura para a construção

\begin{tabular}{|c|c|}
\hline Perguntas de Rother e Harris (2002) & Etapas adaptadas para a construção \\
\hline A- Você escolheu os produtos finais adequados & 1- Escolher a atividade \\
\hline B- Qual é o takt time? & 2- Definir o tempo takt \\
\hline $\begin{array}{l}\text { C- Quais são os elementos de trabalho para se } \\
\text { fazer um item? } \\
\text { D- Qual é o tempo real necessário para cada } \\
\text { elemento de trabalho? }\end{array}$ & $\begin{array}{l}\text { 3- Coletar o tempo das atividades fora do ciclo } \\
\text { repetitivo e reduzi-las } \\
\text { 4- Coletar o tempo dos elementos de trabalho do } \\
\text { ciclo repetitivo e definir o tempo real para executá- } \\
\text { los }\end{array}$ \\
\hline $\begin{array}{l}\text { D- Seu equipamento pode operar de acordo com o } \\
\text { tempo takt? } \\
\text { E- Qual o nível de automação? }\end{array}$ & $\begin{array}{l}\text { 5- Verificar se a máquina pode operar de acordo } \\
\text { com o tempo takt e ajustar se necessário }\end{array}$ \\
\hline $\begin{array}{l}\text { F- Como organizar o processo físico para que uma } \\
\text { pessoa possa fazer um item da maneira mais } \\
\text { eficiente possível? }\end{array}$ & 6- Organizar o leiaute de trabalho \\
\hline $\begin{array}{l}\text { G- Quantos operadores são necessários para } \\
\text { atender ao tempo takt? }\end{array}$ & 7- Calcular quantos funcionários são necessários \\
\hline H- Como distribuir o trabalho entre os operadores? & 8- Distribuir o trabalho entre os funcionários \\
\hline $\begin{array}{l}\text { I- Como você vai programar o processo puxador? } \\
\text { J- Como o processo puxador reagirá às mudanças } \\
\text { da demanda do cliente? }\end{array}$ & - \\
\hline K- Planejamento e implantação & 9- Implementar \\
\hline L- Manutenção e incorporação de melhorias & 10- Manter e melhorar \\
\hline
\end{tabular}

As questões $\mathrm{C}$ e D referem-se à identificação dos elementos de trabalho (questão $\mathrm{C}$ ) e, em seguida, à medição de seus tempos necessários, utilizando-se Folha de Estudo de Processo (FEP). Na manufatura o ciclo repetitivo ocorre em geral em intervalos pequenos, e os operadores são dedicados a seus postos de trabalho, atuando praticamente o turno todo na repetição desses ciclos. $\mathrm{Na}$ construção observa-se que não são claros os ciclos repetitivos e que muitos desperdícios ocorrem em atividades fora dos ciclos repetitivos de agregação de valor. Dessa forma, adotou-se uma adaptação, que foi a análise preliminar das atividades num turno de trabalho, através de uma FEP por turno (Etapa 3), seguida de uma análise dos elementos de trabalho no ciclo repetitivo (Etapa 4). Tanto na etapa 3 quanto na 4 busca-se identificar o que agrega valor ou não, tendo-se como referência a divisão que Ohno (1997) faz do trabalho, em três categorias:

(a) agregam valor: movimentos diretamente necessários para a fabricação de um produto;

(b) trabalho incidental: movimentos que os operadores têm de realizar para a fabricação de um produto, mas que não agregam valor do ponto de vista do cliente; $\mathrm{e}$

(c) desperdício: ações que não agregam valor e que podem ser eliminadas.

As perguntas E e F referem-se a equipamentos. A pergunta $\mathrm{E}$ preocupa-se com o atendimento à capacidade de produção necessária, expressa pelo tempo takt. Resumiram-se essas perguntas na Etapa 5, deixando-se subentendido o aspecto de automação, se necessário, menos relevante no caso da construção. Nesta etapa analisam-se a quantidade e a capacidade das máquinas adotando a FCP.

As perguntas $\mathrm{G}, \mathrm{H}$ e I tiveram somente adaptações de forma, resultando nas Etapas 6, 7 e 8 . Na pergunta $\mathrm{G}$ utiliza-se o diagrama de espaguete; na H, o GBO; e na I, a TCTP e o DTP.

As questões $\mathrm{J}$ e $\mathrm{K}$ dizem respeito à forma como o trabalho é programado e como essa programação chega à célula de trabalho. Na manufatura a programação da produção apresenta interfaces de processos sucessores e compartilhados, sendo, entretanto, sempre possível estabelecer claramente conexão com a demanda do cliente para determinada família de produtos. No caso da construção, a demanda clara do cliente é a data de entrega da obra, expressa pelo cronograma da obra, e a demanda de prazo para cada atividade depende de decisões de planejamento (BULHÔES, 2009; BULHÕES; PICCHI, 2011). As questões J e $\mathrm{K}$ referem-se à forma como um fluxo de valor é programado. Optou-se por deixar esses aspectos fora do método adaptado, considerando que eles seriam tratados e definidos anteriormente à aplicação do método para implementação do TP, através do planejamento da obra.

12 Mariz, R. N.; Picchi, F. A. 
As etapas L e M de Rother e Harris (2002) foram mantidas nas Etapas 9 e 10.

\section{Aplicação do método adaptado: estudos de caso}

O método adaptado foi aplicado nos dois casos, conforme apresentado a seguir. Segundo as características de cada caso, algumas etapas foram focadas prioritariamente em um deles.

\section{Etapa 1: escolher a atividade}

As atividades escolhidas foram o assentamento de porcelanato em piso (Caso 1) e a execução de estaca Franki (Caso 2).

\section{Etapa 2: definir o tempo takt}

No Caso 1, o cronograma da obra estabelecia 9,5 meses para um total 88 apartamentos, resultando em 2,27 dias por apartamento, considerando 21 dias úteis por mês. A obra trabalha em um regime de 9 horas de trabalho de segunda a quinta, e na sexta, 8 horas, resultando em uma média de 8,8 horas por dia trabalhado. Um apartamento tem 934 peças de porcelanatos, e o tempo disponível para executá-lo é de 2,27 dias trabalhados, ou 71.913 segundos, o que gera um tempo takt de 77 segundos por porcelanato $(71.913$ s $/ 934$ porcelanatos). Adotou-se como unidade de análise $o$ assentamento de uma peça de porcelanato, que possibilita uma análise detalhada dos desperdícios.

Para o Caso 2, o cronograma da obra estabelecia que seriam necessários 4,1 meses para executar um total de 509 estacas, portanto o tempo takt é de $1 \mathrm{~h}$ $29 \min 39 \mathrm{~s}$ por estaca, considerando 21 dias úteis por mês e cada dia trabalhado de 8,8 horas. Esse tempo takt pode ter sua unidade traduzida para diferentes processos; por exemplo, cada estaca necessita de 14 betonadas, e cada betonada exige uma viagem (de ida e volta) de minicarregadeira. Portanto, dividindo-se o temo takt de $1 \mathrm{~h} 29 \mathrm{~min}$ $39 \mathrm{~s}$ por estaca por 14, tem-se o tempo takt de 6 $\min 22 \mathrm{~s}$ por traço para betoneira, e de $6 \min 22 \mathrm{~s}$ por viagem para minicarregadeira, ou seja, o takt time é o mesmo, entretanto para cada tipo de atividade específica ele pode ser adaptado sempre com base no valor de $1 \mathrm{~h} 29 \min 39 \mathrm{~s}$ por estaca.

\section{Etapa 3: coletar o tempo das atividades fora do ciclo repetitivo e reduzi-las}

A Etapa 3 foi aplicada somente no Caso 1, onde se observou que possibilitaria uma discussão com mais detalhes, focando-se nas atividades do pedreiro assentador de piso.

Nesta etapa adotaram-se como atividades do ciclo repetitivo somente as atividades que são inerentes ao assentamento, as quais serão analisadas na etapa seguinte. Portanto, fora do ciclo repetitivo ficaram todas as demais atividades, que incluem diversos tipos de desperdícios, como movimentações, esperas, etc., bem como atividades auxiliares, tais como esquadrejamento e nivelamento, corte e limpeza da peça ${ }^{1}$.

Observou-se um dia todo de trabalho (uma sextafeira, $8 \mathrm{~h}$ de trabalho), anotando-se as atividades na folha de estudo de processo em um turno (Quadro 4).

A Figura 1 mostra a porcentagem em relação ao tempo gasto na realização de atividades dentro e fora do ciclo repetitivo.

Pode-se perceber, ao analisar a Figura 1, que 43,8\% ( 3 h 30 min 28 s) do tempo do pedreiro foram empregados na realização de atividades do ciclo repetitivo (assentamento do porcelanato) e $56,2 \%$ (4 h $29 \min 32 \mathrm{~s}$ ) com a realização de atividades fora do ciclo.

Para uma melhor análise das atividades que ocorriam fora do ciclo, foi feito um gráfico de Pareto (Figura 2).

\footnotetext{
${ }^{1}$ Outras definições poderiam ter sido adotadas, como, por exemplo, incluir o corte da peça no ciclo repetitivo. Optou-se por manter a definição do ciclo repetitivo a mais restrita neste Caso 1 , visando a simplificar o foco da etapa 4 neste primeiro estudo exploratório.
} 
Quadro 4 - Trechos da folha de estudo de processo em um turno (Caso 1)

\begin{tabular}{|c|c|c|c|c|}
\hline Período & Horário & Intervalo & $\begin{array}{c}\text { Atividade Executada pelo } \\
\text { Pedreiro }\end{array}$ & Observação \\
\hline \multirow{3}{*}{$\begin{array}{l}\text { Manhã } \\
\text { (início do } \\
\text { trabalho) }\end{array}$} & 07:00:00 & 00:02:49 & - & - \\
\hline & 07:02:49 & 00:09:21 & Esperou por espaçadores & $\begin{array}{l}\text { Horário que tocou o sinal para } \\
\text { início dos serviços no canteiro }\end{array}$ \\
\hline & $07: 12: 10$ & $00: 02: 51$ & $\begin{array}{l}\text { Conversou com outros } \\
\text { funcionários } \\
\end{array}$ & $\begin{array}{c}\text { Ficou esperando em frente ao } \\
\text { almoxarifado da empresa }\end{array}$ \\
\hline \multirow{5}{*}{$\begin{array}{l}\text { Manhã } \\
\text { (meio do } \\
\text { período) }\end{array}$} & 09:14:16 & $00: 00: 54$ & Movimentou-se entre ciclo & - \\
\hline & 09:15:10 & 00:06:08 & Parou para cortar porcelanato & - \\
\hline & 09:21:18 & 00:03:20 & Executou $18^{\circ}$ ciclo & - \\
\hline & $09: 24: 38$ & 00:02:05 & Movimentou-se entre ciclo & - \\
\hline & $09: 26: 43$ & 00:02:39 & Executou $19^{\circ}$ ciclo & - \\
\hline \multirow{5}{*}{$\begin{array}{l}\text { Tarde } \\
\text { (final do } \\
\text { trabalho) }\end{array}$} & $15: 55: 57$ & 00:00:59 & Movimentou-se entre ciclo & - \\
\hline & $15: 56: 56$ & 00:00:04 & Executou $105^{\circ}$ ciclo & - \\
\hline & $15: 57: 00$ & 00:02:19 & $\begin{array}{c}\text { Percebeu que a argamassa não } \\
\text { ia dar para assentar último } \\
\text { porcelanato }\end{array}$ & - \\
\hline & 15:59:19 & 00:00:41 & Guardou suas ferramentas & - \\
\hline & 16:00:00 & - & - & - \\
\hline
\end{tabular}

Nota: Legenda:

$\square$ Execução de atividade do ciclo repetitivo; e

$\square$ Execução de atividade fora do ciclo.

Figura 1 - Distribuição das atividades dentro e fora do ciclo repetitivo (Caso 1)

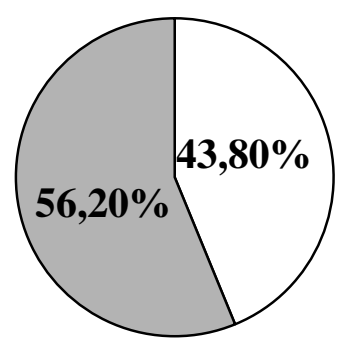

$\square$ execução de atividade no ciclo

$\square$ execução de atividade fora do ciclo

Figura 2 - Divisão das atividades realizadas fora do ciclo repetitivo (Caso 1)

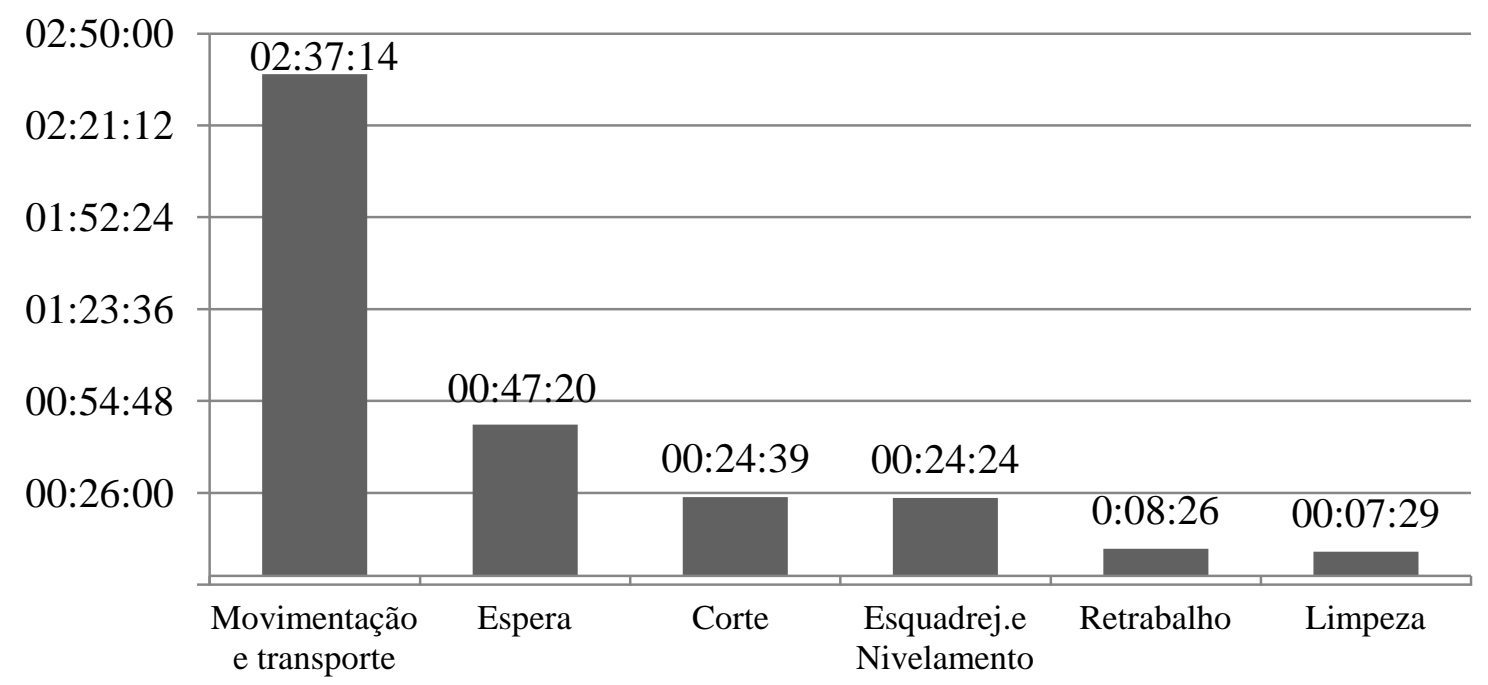

14 Mariz, R. N.; Picchi, F. A. 
As atividades de movimentação e transporte representaram $32 \%$ do tempo. As mais frequentes foram: pegar argamassa, deslocar balde de água, deslocar argamasseira, pegar caixas de porcelanato, abrir caixas de porcelanato, movimentar para assentar outro porcelanato, deslocar material, equipamento e equipe para outro compartimento, pegar espaçadores em porcelanato já assentado para reaproveitar em outros e deslocar-se até o riscador ou serra circular. Observou-se que boa parte desses movimentos do assentador foi ocasionada pela falta do ajudante no momento necessário, pois ele atendia dois assentadores, em andares diferentes.

A espera representou $10 \%$, em geral no início de períodos, como, por exemplo, pela manhã, aguardando espaçadores, e após o almoço, com início após o horário previsto.

O corte e o esquadrejamento/prumo representaram cada um 5\% do tempo do pedreiro e são atividades necessárias, apesar de fora do ciclo repetitivo.

O retrabalho, 2\% do tempo, deveu-se à quebra de 3 porcelanatos, 2 deles no corte.

A limpeza da área, também em torno de $2 \%$, foi feita no início do dia.

O tempo dispendido em movimentações e transporte, mais espera e retrabalho representam $44 \%$ ( 3 h 33 min de um dia de 8 h) e podem ter um plano de eliminação com ações tais como modificação do leiaute de trabalho (passo 6), trabalho padronizado do ajudante (evitando que o assentador tenha de se deslocar), abastecimento adequado, etc. Esse número mostra que há um potencial teórico de praticamente dobrar o tempo dedicado pelo assentador ao assentamento em si (ciclo repetitivo) em um dia.

As atividades auxiliares, de esquadrejamento e corte, que juntas representam outros $10 \%$, apresentam também potencial de racionalização, através de estudos detalhados, como os descritos para as atividades do ciclo repetitivo descritas na etapa 4 , podendo, inclusive, incluir na análise do ciclo repetitivo, ou de combinação do trabalho padronizado do assentador e do ajudante, ou outras formas que possibilitem ganhos de produtividade $\mathrm{e}$ sua redução.

\section{Etapa 4: coletar o tempo dos elementos de trabalho do ciclo repetitivo e definir o tempo real para executá-los}

No Caso 2, a etapa 4 foi aplicada estudando-se mais de um operador, de forma a propiciar uma discussão mais rica das análises desta etapa. Focou-se somente o processo de dosagem, mistura e transporte do concreto para a execução da estaca. Neste estudo utilizou-se a FEP em duas partes, uma para coletar as atividades executadas pelo operador da betoneira (ou betoneiro) e outra para coletar as atividades executadas pelo ajudante do operador da betoneira e pelo operador da minicarregadeira.

A Tabela 1 mostra a parte 1 da FEP, onde se pode ver o ciclo de trabalho do betoneiro, indicando os elementos de trabalho e respectivos tempos.

Conforme proposto no método de Rother e Harris (2002), indica-se, para cada elemento de trabalho, o menor tempo repetitivo, cuja soma, neste exemplo da Tabela 1, resulta em um total de $194 \mathrm{~s}$. Essa soma dos menores valores repetitivos de cada elemento de trabalho (e não, por exemplo, a soma de suas médias) tem o significado, no método, de estabelecer uma meta bastante exigente, que demandará diversas melhorias (leiaute e projeto do posto de trabalho, abastecimento, treinamento, etc.), para que este conteúdo total de trabalho seja atingido consistentemente. Mesmo em ambientes com inúmeros fatores de instabilidade, como a construção, onde a sustentação desses menores tempos repetitivos possa ter dificuldades, este cálculo mantém seu significado de expressar um ganho máximo potencial que direciona ações de melhoria e busca de estabilidade.

A partir dos dados gerados pela FEP, elaborou-se o gráfico de balanceamento de operador atual. $\mathrm{Na}$ Figura 3 pode-se verificar a distribuição da carga de trabalho para cada operador e auxiliar.

Pode-se perceber, ao analisar a Figura 3, que o tempo de ciclo dos operadores e do auxiliar ficou abaixo do tempo takt, ou seja, mostram oportunidades de melhorias. Na etapa 7 será proposto um novo GBO, para que se possa atingir melhorias no estado futuro. 
Tabela 1 - Folha de estudo de processo da dosagem e transporte de concreto para estaca Franki - Caso 2 (parte 1)

\begin{tabular}{|c|c|c|c|c|c|c|c|c|}
\hline $\begin{array}{c}\text { Estudo do } \\
\text { processo }\end{array}$ & \multicolumn{2}{|c|}{ Operador } & \multirow{2}{*}{$\begin{array}{l}\text { Betoneiro } \\
1 \text { Colocar } \\
4 \text { baldes } \\
\text { de água } \\
\text { na } \\
\text { betoneira }\end{array}$} & \multirow[b]{2}{*}{$\begin{array}{l}\text { Betoneiro } \\
2 \text { Virar } \\
\text { betoneira } \\
\text { e } \\
\text { despejar } \\
\text { cimento e } \\
\text { agregados } \\
\text { da } \\
\text { caçamba } \\
\text { na } \\
\text { betoneira }\end{array}$} & \multirow{2}{*}{$\begin{array}{l}\text { Betoneiro } \\
3 \text { Colocar } \\
\text { mais } 1 \\
\text { balde de } \\
\text { água }\end{array}$} & \multirow{2}{*}{\begin{tabular}{l}
\multicolumn{1}{c}{ Betoneiro } \\
4 Girar \\
manivela da \\
betoneira para \\
preparar \\
descarregamento
\end{tabular}} & \multirow{2}{*}{\begin{tabular}{l}
\multicolumn{1}{c}{ Betoneiro } \\
5 Descarregar \\
concreto na \\
mincarregadeira
\end{tabular}} & \multirow[b]{2}{*}{ Total } \\
\hline $\begin{array}{l}\text { Processo: } \\
\text { Dosagem e } \\
\text { transporte } \\
\text { de } \\
\text { concreto }\end{array}$ & Funcionário: & $\begin{array}{l}\text { Elemento } \\
\text { de } \\
\text { trabalho }\end{array}$ & & & & & & \\
\hline \multirow{11}{*}{$\begin{array}{l}\text { Realizado } \\
\text { por: } \\
\text { Renato } \\
\text { Mariz }\end{array}$} & \multirow{10}{*}{\multicolumn{2}{|c|}{ Tomada de tempos }} & $30 \mathrm{~s}$ & $53 \mathrm{~s}$ & $43 \mathrm{~s}$ & $11 \mathrm{~s}$ & $334 \mathrm{~s}$ & $471 \mathrm{~s}$ \\
\hline & & & $18 \mathrm{~s}$ & $72 \mathrm{~s}$ & $31 \mathrm{~s}$ & $13 \mathrm{~s}$ & $250 \mathrm{~s}$ & $384 \mathrm{~s}$ \\
\hline & & & $23 \mathrm{~s}$ & $58 \mathrm{~s}$ & $32 \mathrm{~s}$ & $14 \mathrm{~s}$ & $230 \mathrm{~s}$ & $357 \mathrm{~s}$ \\
\hline & & & $37 \mathrm{~s}$ & $50 \mathrm{~s}$ & $17 \mathrm{~s}$ & $15 \mathrm{~s}$ & $163 \mathrm{~s}$ & $282 \mathrm{~s}$ \\
\hline & & & $18 \mathrm{~s}$ & $51 \mathrm{~s}$ & $29 \mathrm{~s}$ & $10 \mathrm{~s}$ & $99 \mathrm{~s}$ & $207 \mathrm{~s}$ \\
\hline & & & $16 \mathrm{~s}$ & $57 \mathrm{~s}$ & $36 \mathrm{~s}$ & $16 \mathrm{~s}$ & $236 \mathrm{~s}$ & $361 \mathrm{~s}$ \\
\hline & & & $16 \mathrm{~s}$ & $238 \mathrm{~s}$ & $24 \mathrm{~s}$ & $10 \mathrm{~s}$ & $75 \mathrm{~s}$ & $363 \mathrm{~s}$ \\
\hline & & & $20 \mathrm{~s}$ & $57 \mathrm{~s}$ & $33 \mathrm{~s}$ & $17 \mathrm{~s}$ & $115 \mathrm{~s}$ & $242 \mathrm{~s}$ \\
\hline & & & $18 \mathrm{~s}$ & $47 \mathrm{~s}$ & $18 \mathrm{~s}$ & $8 \mathrm{~s}$ & $127 \mathrm{~s}$ & $218 \mathrm{~s}$ \\
\hline & & & $19 \mathrm{~s}$ & $51 \mathrm{~s}$ & $37 \mathrm{~s}$ & $9 \mathrm{~s}$ & $101 \mathrm{~s}$ & $217 \mathrm{~s}$ \\
\hline & \multicolumn{2}{|c|}{ Tempo de máquina } & & & $10 \mathrm{~s}$ & $180 \mathrm{~s}$ & & \\
\hline $\begin{array}{l}\text { Data/Hora: } \\
\text { 26/11/2011 }\end{array}$ & \multicolumn{2}{|c|}{ Menor repetitivo } & $16 \mathrm{~s}$ & $51 \mathrm{~s}$ & $18 \mathrm{~s}$ & $10 \mathrm{~s}$ & $99 \mathrm{~s}$ & $194 \mathrm{~s}$ \\
\hline Página: 1 & \multicolumn{2}{|l|}{ Observações } & & & & $\begin{array}{l}\text { Betoneiro parado } \\
\text { cerca de } 3 \mathrm{~min} \\
\text { enquanto a } \\
\text { betoneira } \\
\text { funciona }\end{array}$ & & \\
\hline
\end{tabular}

Figura 3 - Gráfico de balanceamento dos operadores (estado atual) - Caso 2

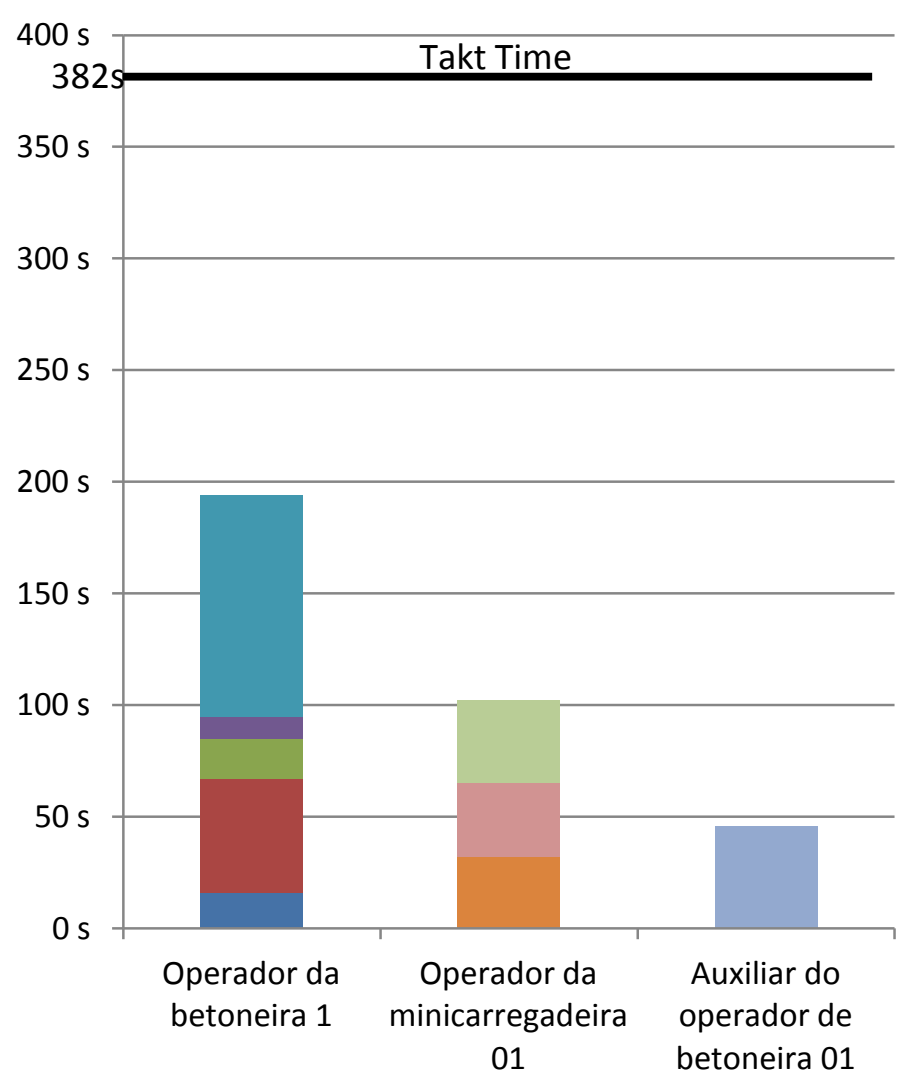

9-Colocar mais brita na caçamba da betoneira

8-Colocar areia na caçamba da betoneira

7-Pegar 2 sacos de cimento, colocá-las na caçamba da betoneira e abri-las

6-Colocar brita na caçamba da betoneira

5-Descarregar concreto na mini carregadeira

4-Girar manivela da betoneira para preparar descarregamento

- 3-Colocar mais 1 balde d'água

2-Virar betoneira e despejar cimento e agregados da caçamba na betoneira

1-Colocar 4 baldes de água na betoneira 


\section{Etapa 5: verificar se a máquina pode operar de acordo com o tempo takt e ajustar se necessário}

No Caso 1, o único equipamento envolvido era a betoneira, que não foi estudada, uma vez que o caso focou o trabalho do assentador de porcelanato. A etapa 5 foi explorada somente no Caso 2, o qual envolvia três betoneiras, quatro máquinas de bate-estaca e quatro minicarregadeiras (uma minicarregadeira abastecia as betoneiras com agregado, e as demais transportavam concreto).

Elaborou-se a FCP (Folha de Capacidade de Produção) para analisar a capacidade produtiva de cada máquina (Tabela 2).
A Tabela 2 foi elaborada com base nos tempos de ciclo levantados in loco por cada máquina. Por exemplo, o bate-estaca tem um tempo de ciclo de $120 \mathrm{~min} /$ estaca (100 de tempo básico + $20 \mathrm{~min}$ de mobilização, ao final de cada cravação de estaca). Como um dia de trabalho tem 528 min, ao dividirse este valor por $120 \mathrm{~min}$, chega-se a 4,4 estacas por dia como capacidade máxima de cada bateestaca. O tempo considerado manual foi aquele no qual havia intervenção humana, ou seja, a máquina não trabalhava, a não ser que tivesse um operador.

Com base nos tempos de ciclo da Tabela 2, e considerando-se o número de equipamentos de cada tipo, elaborou-se o Gráfico de Balanceamento de Máquina (GBM), apresentado na Figura 4, que segue a mesma representação que o GBO, focando máquinas, e não os operadores.

Tabela 2 - Folha de Capacidade de Produção (estaca Franki) - Caso 2

\begin{tabular}{|c|c|c|c|c|c|c|c|c|}
\hline \multirow{2}{*}{\multicolumn{2}{|c|}{$\begin{array}{c}\text { Folha de } \\
\text { Capacidade do } \\
\text { Processo }\end{array}$}} & \multirow{4}{*}{$\begin{array}{l}\text { Aprovado por: } \\
\text { Nome da } \\
\text { máquina }\end{array}$} & \multirow{2}{*}{\multicolumn{3}{|c|}{$\begin{array}{l}\text { Serviço: Estaca Franki } \\
\text { Aplicação: Fundação }\end{array}$}} & \multirow{2}{*}{\multicolumn{2}{|c|}{ Takt time/dia: 6 estacas }} & \multirow{4}{*}{$\begin{array}{c}\text { Registrado por: } \\
\begin{array}{c}\text { Capacidade de } \\
\text { processamento } \\
\text { por dia }\end{array}\end{array}$} \\
\hline & & & & & & & & \\
\hline \multirow{2}{*}{$\mathbf{N}^{\mathbf{o}}$} & \multirow{2}{*}{$\begin{array}{l}\text { Nome do } \\
\text { processo }\end{array}$} & & \multicolumn{3}{|c|}{ Tempo Básico (min) } & \multicolumn{2}{|c|}{$\begin{array}{c}\text { Tempo para } \\
\text { manutenção/mobilização }\end{array}$} & \\
\hline & & & Manual & Auto & Total & $\mathrm{N}^{0}$ peças/troca & $\begin{array}{c}\text { Tempo } \\
\text { (min) }\end{array}$ & \\
\hline 1 & $\begin{array}{l}\text { Dosagem de } \\
\text { concreto }\end{array}$ & Betoneira & 45 & 42 & 87 & ao final do turno & 30 & 5,7 estacas \\
\hline 2 & $\begin{array}{l}\text { Transporte } \\
\text { de concreto }\end{array}$ & Mini carregadeira & 40 & 0 & 40 & ao final do turno & 30 & 12,6 estacas \\
\hline 3 & $\begin{array}{l}\text { Transporte } \\
\text { de agregados }\end{array}$ & Minicarregadeira & 23 & 0 & 23 & ao final do turno & 30 & 21,7 estacas \\
\hline 4 & $\begin{array}{l}\text { Cravação e } \\
\text { congretagem } \\
\text { de estaca }\end{array}$ & Bate-estaca & 100 & 0 & 100 & 1 & 20 & 4,4 estacas \\
\hline
\end{tabular}

Figura 4 - Gráfico de Balanceamento de Máquinas (estado atual) - Caso 2

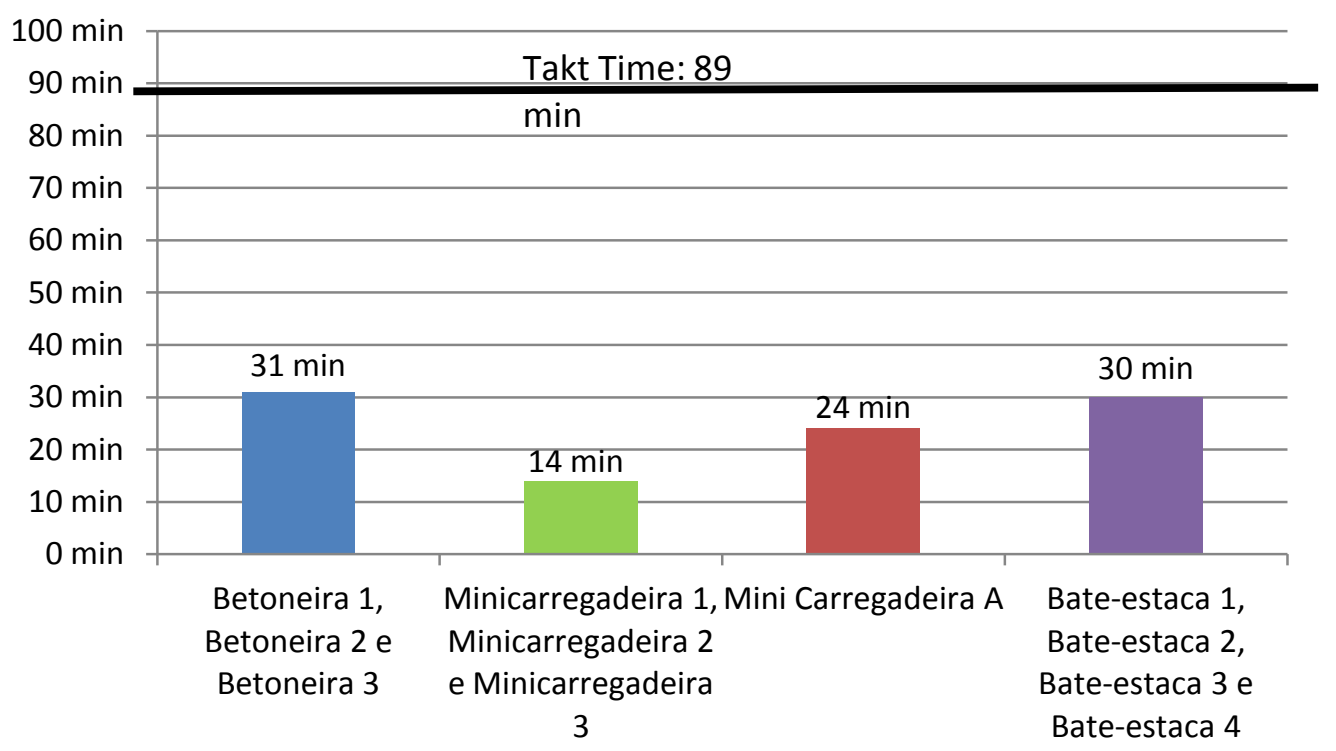


Para o tempo takt de 1 h 29 m 39 s por estaca, ou $90 \mathrm{~min} / \mathrm{estaca}$, considerando-se $8,8 \mathrm{~h} / \mathrm{dia}$, obtém-se uma demanda de 5,87 estacas/dia. Considerandose segurança e fatores práticos, pode-se considerar a demanda diária arredondada de 6 estacas por dia. O número de betoneiras necessárias calculadas pelo método seria de 1,05 , obtendo-se o mesmo dividindo essa demanda pela capacidade diária do equipamento da Tabela $2(6 / 5,7)$; os gerentes da obra poderiam adotar melhorias para viabilizar o uso de apenas uma betoneira ou assumir o uso de duas, arredondando para cima e obtendo proteção contra eventuais instabilidades. Seguindo-se o mesmo cálculo para os demais equipamentos, chega-se às necessidades de uma minicarregadeira para concreto $(6 / 12,6=0,47)$, uma para agregados $(6 / 21,7=0,27)$ e dois bate-estacas $(6 / 4,4=1,36)$. Essa situação encontra-se ilustrada no GBM estado futuro (Figura 5). Mesmo que se adote um tempo de ciclo planejado igual a $80 \%$ do tempo takt, como indicado na Figura 5, observa-se que esse número de equipamentos seria suficiente.

\section{Etapa 6: organizar o leiaute do trabalho}

No caso 2, o leiaute abrange a distribuição dos bate-estacas e betoneiras no canteiro e as rotas das minicarregadeiras, os quais tinham sido definidos pelo engenheiro da obra em estudos anteriores.

Esta etapa foi analisada em detalhes no Caso 1. Foi elaborado um diagrama de espaguete (Figura 6), que evidenciou os desperdícios com transporte e deslocamento ocorridos no $6^{\circ}$ pavimento.

Pode-se observar, ao analisar o diagrama de espaguete, que as caixas de porcelanato se encontravam em um compartimento que ficava distante do apartamento no qual o pedreiro estava assentando o porcelanato.

Observa-se, ainda, que o pedreiro teve de ir ao $14^{\circ}$ pavimento procurar a argamasseira para dosar a argamassa. Foi também ao $7^{\circ}$ pavimento ligar a extensão, pois no $6^{\circ}$ pavimento não havia tomadas. O pedreiro ainda foi 2 vezes ao pavimento térreo, uma para almoçar (desconsiderada no diagrama de espaguete) e outra para buscar o capacete, que esqueceu após o almoço. Além disso, deslocou-se bastante para fazer corte nos porcelanatos, pois a bancada da serra circular era fixa na varanda.

Mediante uma estimativa, calculou-se a distância percorrida em um dia de trabalho, somente com atividades realizadas fora do ciclo, de $529 \mathrm{~m}$ (desconsiderou-se o deslocamento até o posto de trabalho, a saída ao final do expediente e movimentações na realização no ciclo).

Figura 5 - Gráfico de Balanceamento de Máquinas (estado futuro) - Caso 2

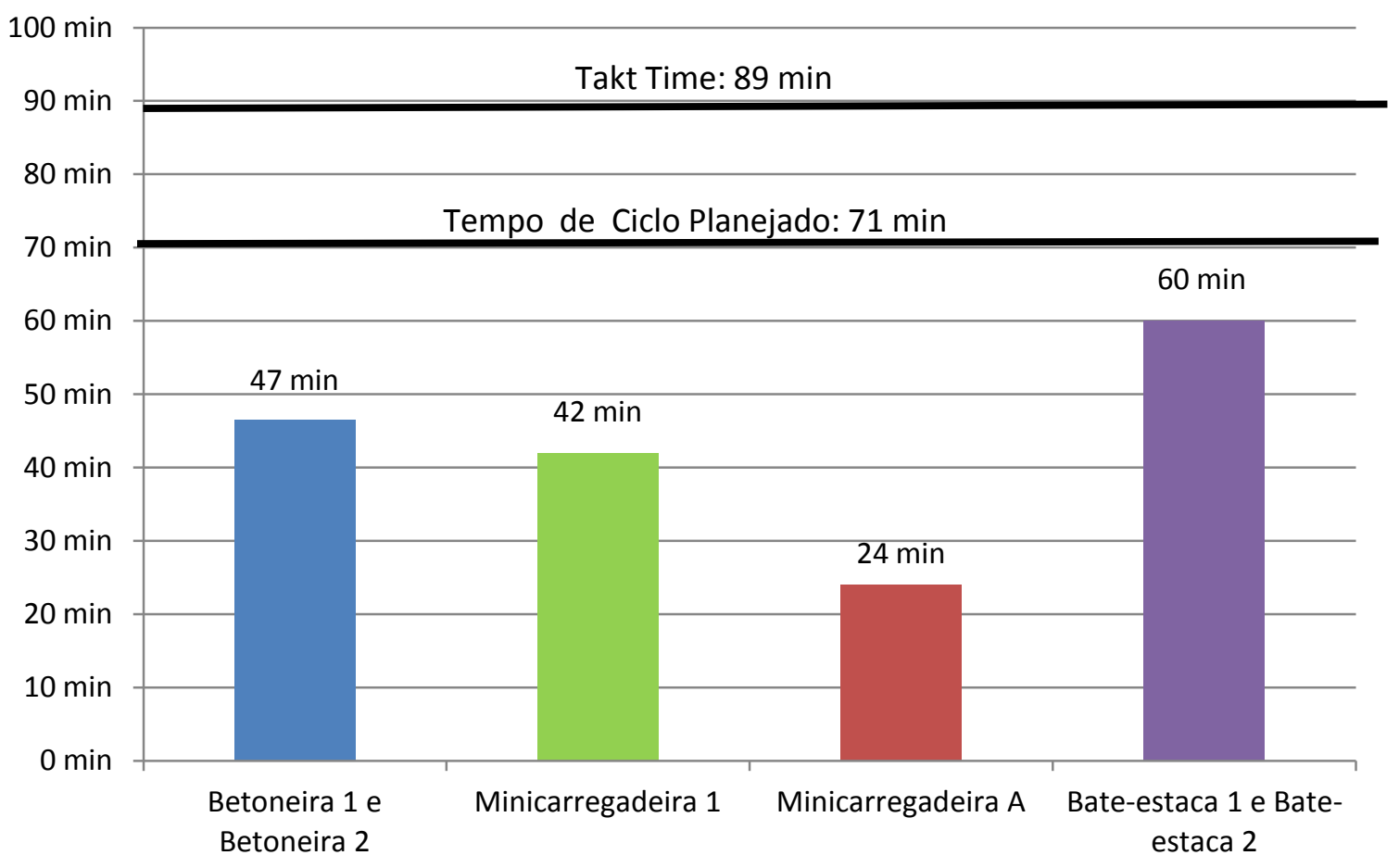

18 Mariz, R. N.; Picchi, F. A. 
Figura 6 - Diagrama de espaguete do $6^{\circ}$ pavimento observado em um cômodo - Caso 1

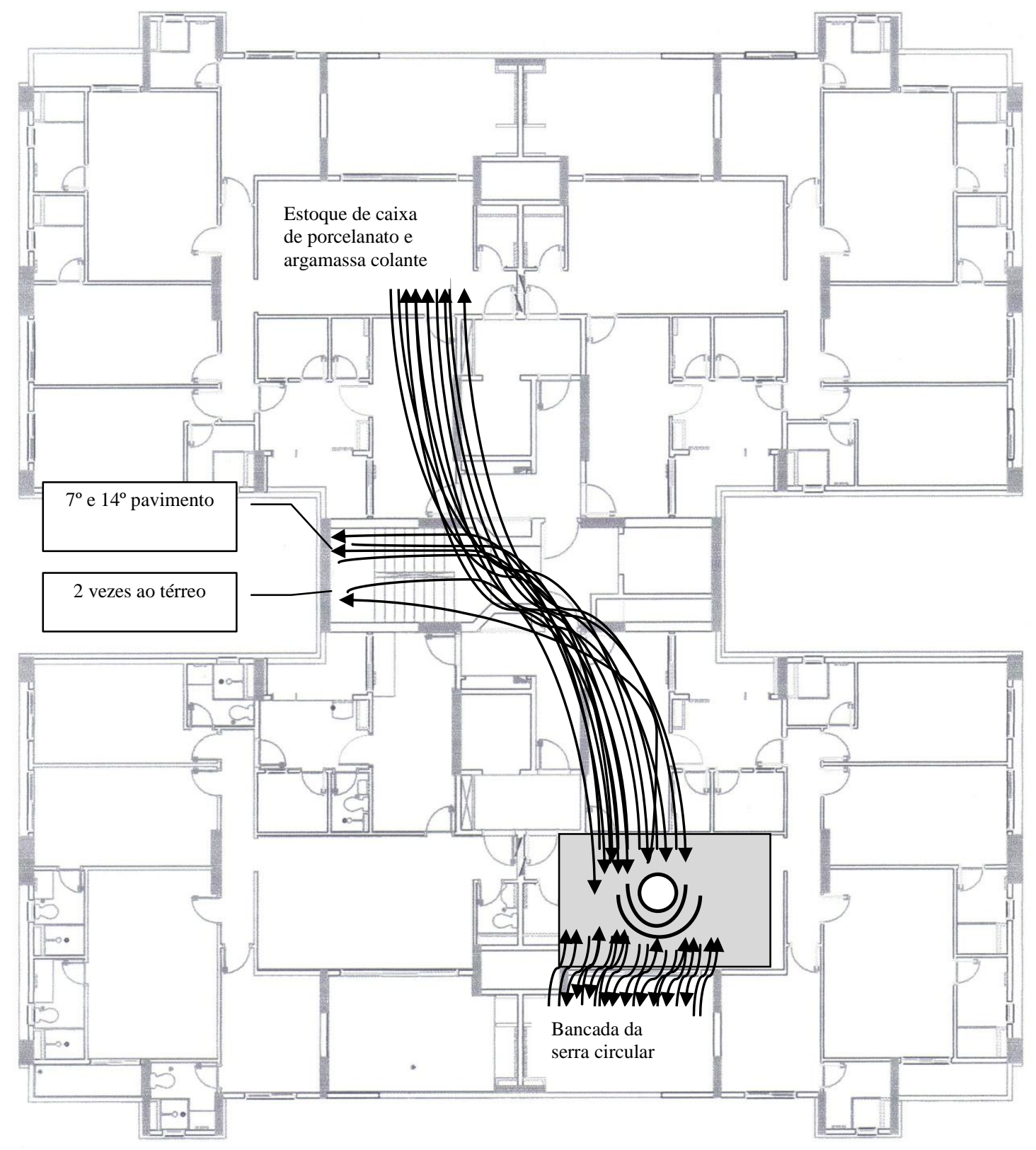

Muito desse tempo desperdiçado com deslocamento e transporte poderia ser minimizado com uma organização do leiaute do apartamento, por meio de abastecimento do porcelanato e argamassa, que seria dimensionado para um apartamento e posicionado antes da chegada pela equipe de planejamento da empresa, podendo ser utilizada a produção puxada por meio de kanban.

Com esse intuito, foi elaborado um leiaute para estocar a argamassa e o porcelanato, como mostra a Figura 7. Para a elaboração dessa distribuição de paletes no pavimento, foi calculada a quantidade real necessária de porcelanato e de argamassa colante para execução de um apartamento. Por exemplo, foi calculada a necessidade de 33 sacos de argamassa colante por apartamento, sendo os mesmos distribuídos no pavimento, conforme a Figura 7, em 11 paletes de 3 sacos cada.

\section{Etapa 7: calcular quantos funcionários são necessários}

O método de Rother e Harris (2002) adota uma postura para esse cálculo que induz a melhorias bastante exigentes, tomando a soma do menor tempo repetitivo de cada elemento de trabalho (calculado na FEP na etapa 4), já eliminando atividades que não agregam valor (chamado kaizen no papel por esses autores) e dividindo essa soma 
pelo tempo takt. Isso leva a metas e sucessivos kaizens, que têm resultado, na manufatura, em se atingir a viabilização da produção no tempo takt com esse número de operadores calculados. No caso da construção, uma série de condições de estabilidade precisaria ser atingida para que se viabilizasse esse mesmo ideal.

Uma adaptação proposta nesta etapa é a de adotarse $20 \%$ do tempo para descanso e redução do ritmo, com base no estudo sobre amostragem de trabalho de Thomas (1992), para o estabelecimento de um tempo de ciclo planejado (portanto, 20\% abaixo do tempo takt). O número de funcionários necessários, nesse caso, seria obtido pela divisão da soma do menor tempo repetitivo dos elementos de trabalho pelo tempo de ciclo planejado, e não pelo tempo takt.

Tomando-se como exemplo o Caso 2, pegando-se os dados do GBO - estado atual (Figura 3) e adotando-se o cálculo pelo tempo de ciclo planejado de $80 \%$ do tempo takt $(0,8 * 382=301 \mathrm{~s})$, teríamos:
(a) operador de betoneira: 194/301 $=0,65$;
(b) operador de minicarregadeira: 102/301=0,34; e
(c) auxiliar de operador de betoneira: $46 / 301=0,15$.
A partir desses cálculos, poder-se-ia concluir, por exemplo, que um operador de betoneira seria suficiente para realizar todos os elementos de trabalho dentro do tempo de ciclo planejado, e ainda poderia absorver as atividades do auxiliar. Isso mostra um potencial bastante desafiador, uma vez que a obra estava utilizando para essa operação 3 operadores de betoneira e 3 auxiliares.

Figura 7 - Leiaute projetado para disposição do material e bancada móvel - Caso 1

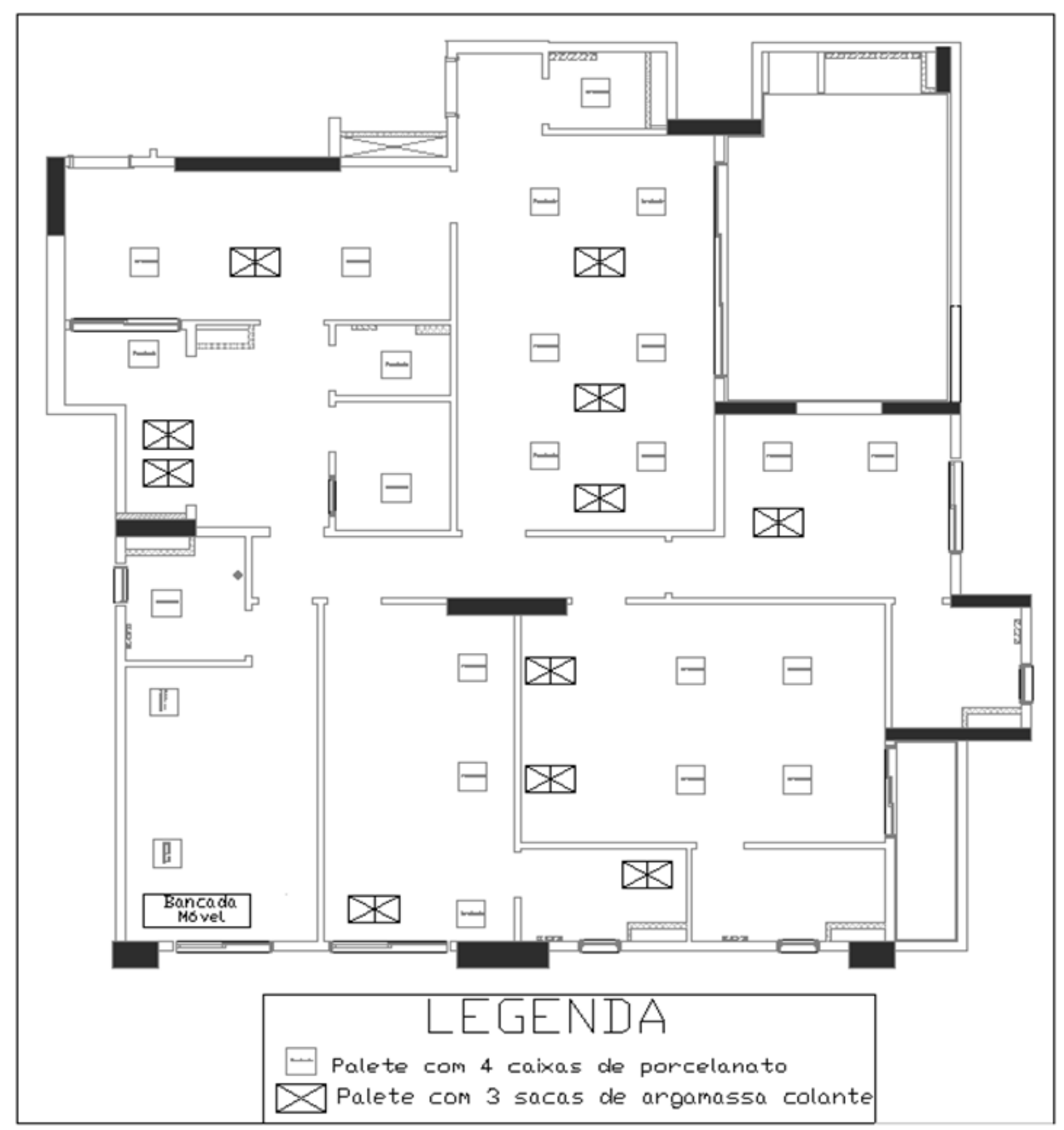

20 Mariz, R. N.; Picchi, F. A. 


\section{Etapa 8: distribuir o trabalho entre os funcionários}

No Caso 1 foi analisado somente um operador. O Caso 2 possibilita uma melhor discussão desta etapa. Adotando-se o número de funcionários na Etapa 7, a distribuição de trabalho entre eles é apresentada na Figura 8 - GBO futuro.

A distribuição do trabalho dos operadores pode ser detalhada por meio de outros documentos, apresentando-se como exemplos a TCTP - Tabela de Combinação de Trabalho Padronizado (Figura 9) e o DTP - Diagrama de Trabalho Padronizado (Figura 10). Esses documentos mostram como o operador de betoneira interagiria com as duas betoneiras (discutido na Etapa 5), dentro de seu ciclo de trabalho.

\section{Etapas 9 e 10: implementar e manter e melhorar}

Estas etapas não foram objeto deste estudo exploratório. Abrangeriam a implementação do trabalho padronizado a que se chegou, com a divulgação dos documentos gerados, treinamento dos funcionários, acompanhamento, etc.

\section{Discussão}

A sequência de etapas do método direcionou uma análise sistemática, que auxilia na identificação e quantificação dos desperdícios, bem como orienta o planejamento de melhorias para a redução desses desperdícios. Como resultado, o método leva ao estabelecimento de um trabalho padronizado, em uma situação futura com menos desperdícios, definindo o tempo takt, tempo de ciclo planejado, número de operadores e equipamentos, sequência de atividades, estoques padrão em processo, leiaute, pontos de atenção de segurança e qualidade.

Figura 8 - Gráfico de Balanceamento dos Operadores (estado futuro) - Caso 2

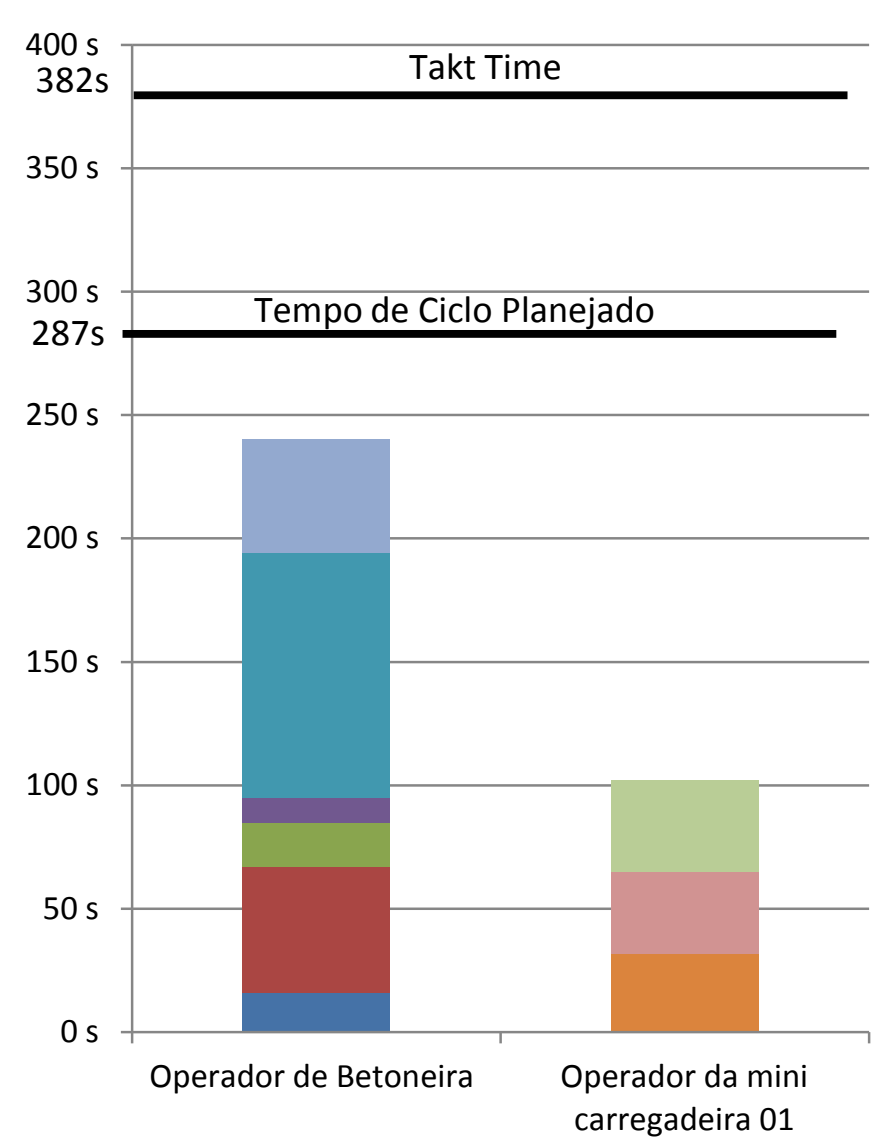

9-Colocar mais brita na caçamba da betoneira

8-Colocar areia na caçamba da betoneira

7-Pegar 2 sacos de cimento, colocá-los na caçamba da betoneira e abri-las 6-Colocar brita na caçamba da betoneira

5-Descarregar concreto na minicarregadeira

4-Girar manivela da betoneira para preparar descarregamento

3-Colocar mais 1 balde d'água

- 2-Virar betoneira e despejar cimento e agregados da caçamba na betoneira - 1-Colocar 4 baldes de água na betoneira 
Figura 9 - Tabela de combinação do trabalho padronizado de produção de argamassa - Caso 2

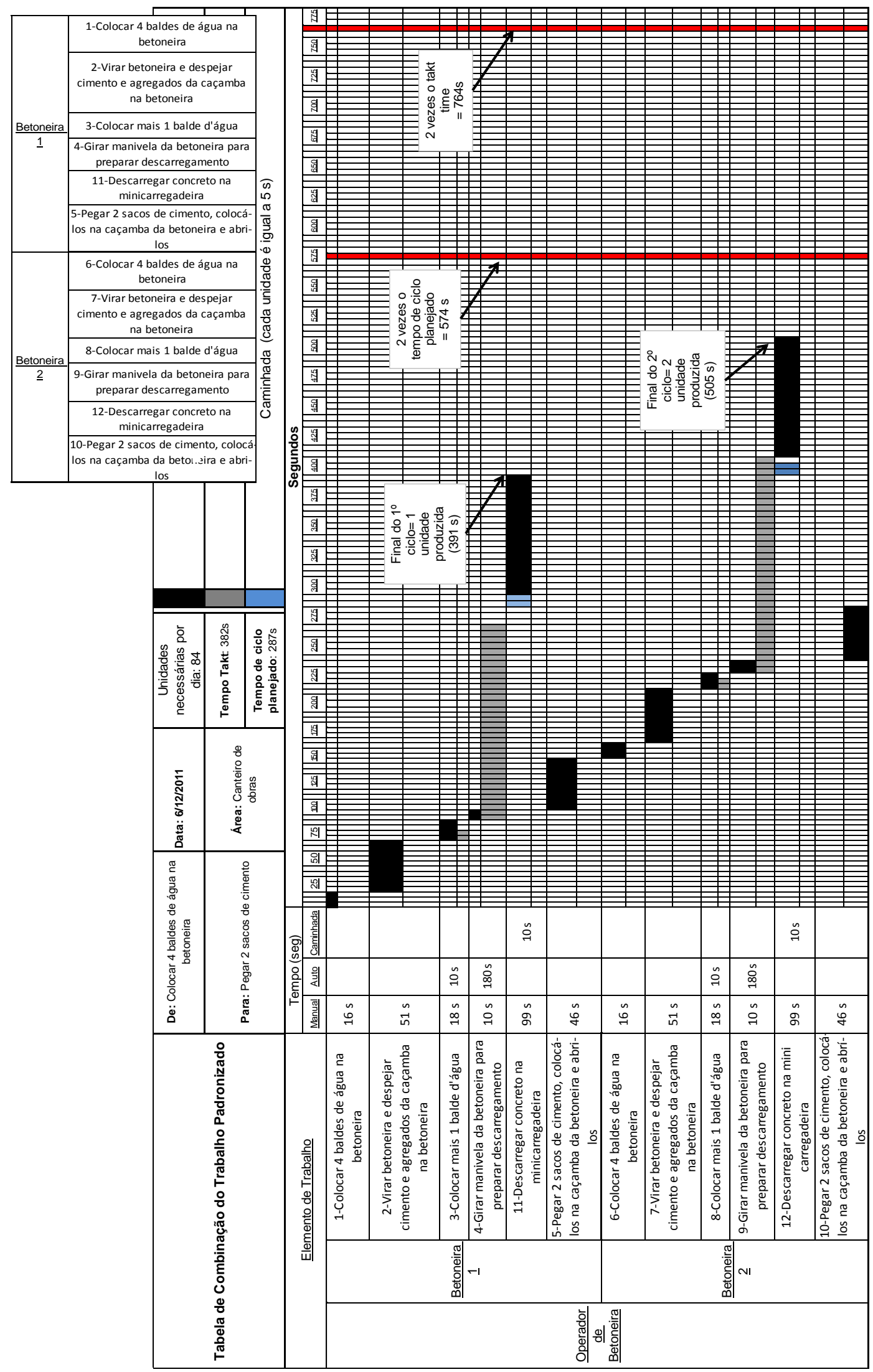


Figura 10 - Diagrama de trabalho padronizado para produção de argamassa - Caso 2

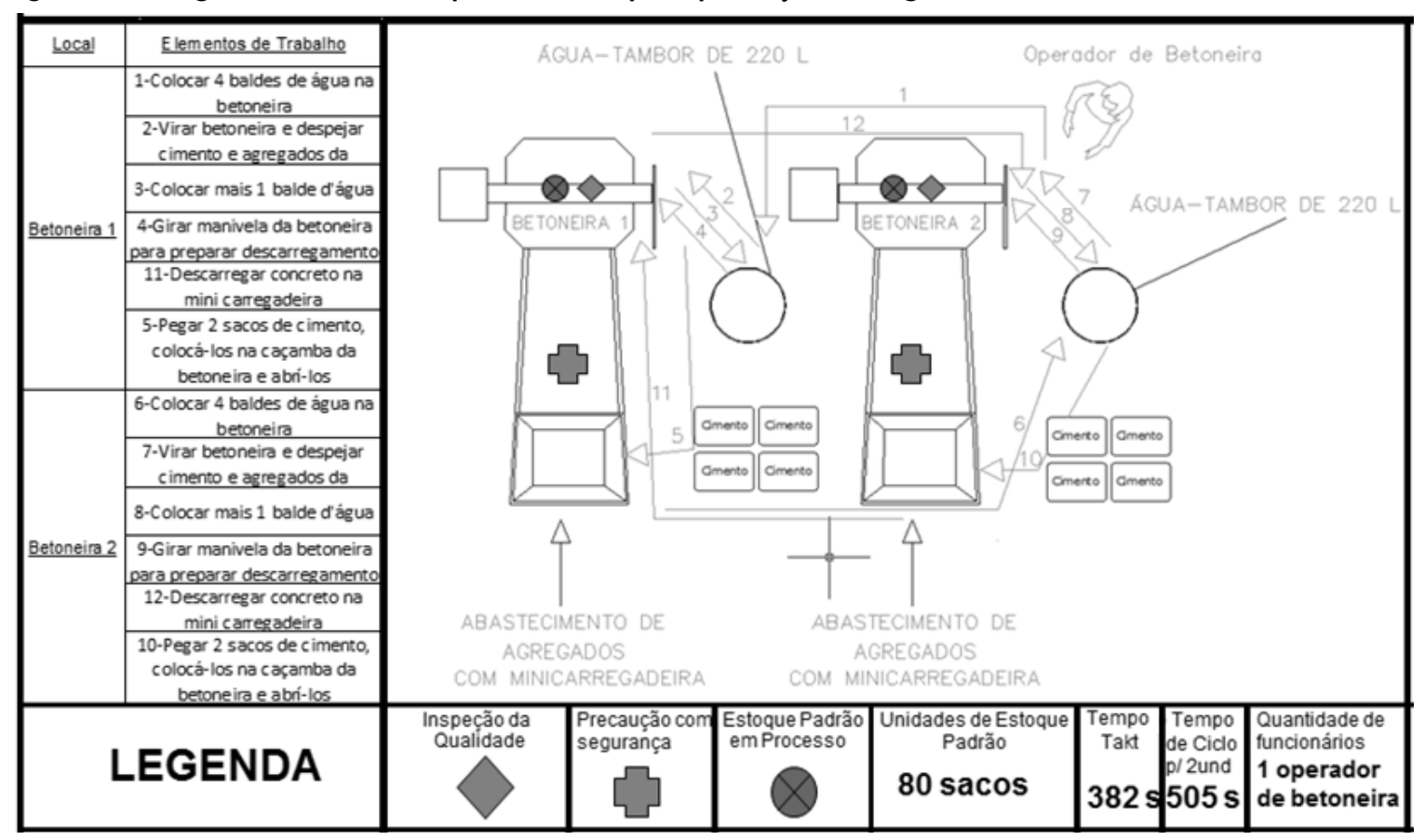

O método mostrou-se aplicável e de utilidade para seus objetivos, no ambiente de construção. Os documentos utilizados atenderam a seus propósitos:

(a) Folha de Estudo de Processo (FEP): propiciou a análise de atividades no turno, bem como a análise de elementos de trabalho no ciclo repetitivo, e em ambos os casos serve para identificar desperdícios. No caso do ciclo repetitivo, aponta o tempo ideal para cada elemento de trabalho através do menor repetido;

(b) Gráfico de Balanceamento do Operador (GBO): já aplicado na construção por outros autores, como Bulhões (2009), Bulhões e Picchi (2011), Francelino et al. (2006) e Souza et al. (2005), possibilitou a análise da distribuição dos elementos de trabalho;

(c) Diagrama de espaguete: possibilitou a identificação de movimentos desnecessários e o planejamento de leiaute futuro;

(d) Folha de Capacidade de Produção (FCP): possibilitou o dimensionamento no número de equipamentos necessários;

(e) Gráfico de Balanceamento de Máquinas (GBM): complementou a análise propiciada pela FCP;

(f) Tabela de Combinação do Trabalho Padronizado (TCTP): possibilitou a análise da distribuição do trabalho entre operadores e da interação entre estes e os equipamentos; e (g) Diagrama de Trabalho Padronizado: registrou o tempo takt, leiaute, atividades, cuidados de segurança e qualidade, e diversos outros elementos do TP.

Os resultados potenciais apontados são bastante significativos.

No Caso 1, a análise das atividades fora do ciclo repetitivo mostrou que das $8 \mathrm{~h}$ de trabalho apenas $43,8 \%$, ou $3,5 \mathrm{~h}$, eram empregadas no ciclo repetitivo, demonstrando potencial de praticamente se dobrar esse número, ainda mantendo uma folga entre tempo de ciclo planejado e tempo takt de $20 \%$. Na análise do ciclo repetitivo, observou-se outro potencial de praticamente dobrar a produtividade, caso seja alcançada a estabilização do menor tempo repetido dos elementos de trabalho.

No Caso 2, a obra no estado atual estava usando um total de 11 equipamentos (3 betoneiras, 4 minicarregadeiras (3 para concreto e 1 para agregados) e 4 bate-estacas. Os equipamentos eram alugados, portanto qualquer redução representaria economia imediata. Os número calculados através desta etapa mostraram que 6 equipamentos seriam suficientes ( 2 betoneiras, 2 minicarregadeiras e 2 bate-estacas). A obra estava utilizando para a operação de produção do concreto e carregamento de agregados um total de 7 funcionários (3 operadores de betoneira, 3 auxiliares e 1 operador de minicarregadeira para agregados). Após a análise, chegou-se à 
necessidade de 2 funcionários (1 operador de betoneira e 1 operador de minicarregadeira).

Esses ganhos são potenciais e baseados nos cálculos teóricos, e a comprovação de sua viabilidade depende de aplicação, teste, manutenção e melhoria, mas têm a relevância de apontarem metas e direcionarem formas de buscálas.

\section{Método proposto para aplicação do trabalho padronizado no contexto da construção}

Como resultado da aplicação das etapas nos casos descritos, gerou-se um método para aplicação do trabalho padronizado no contexto da construção. Esse método é constituído de fluxograma (Figura 11) e do Quadro 5.

\section{Considerações finais}

O método proposto toma como base um método utilizado na manufatura. Adaptações de forma e de conteúdo foram utilizadas, visando a sua adequação ao contexto da construção. Em termos de conteúdo, as maiores mudanças foram no que se refere à análise de atividades fora do ciclo repetitivo, que expuseram um foco de análise que mostrou importantes desperdícios. Também na forma de cálculo do número de operadores adotouse como base o tempo de ciclo planejado igual a $80 \%$ do tempo takt, e não o tempo takt, considerando-se as condições de realização das atividades na construção.

De maneira geral, os documentos utilizados para a análise do trabalho padronizado na manufatura sofreram adaptações mínimas de linguagem e mostraram utilidade para seus propósitos também no ambiente da construção.

\section{Figura 11 - Método proposto para a aplicação do TP no contexto da construção}

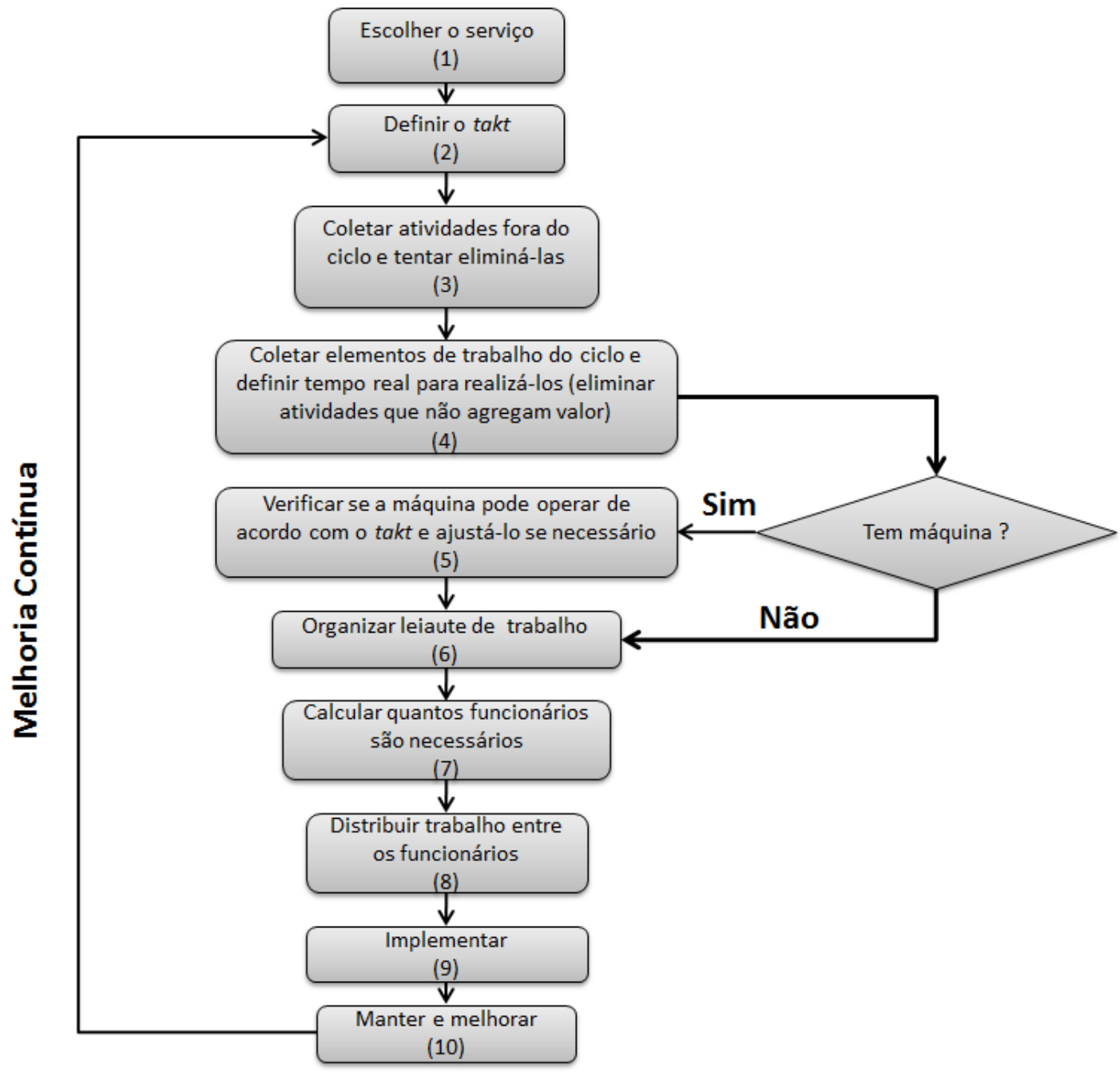

24 Mariz, R. N.; Picchi, F. A. 


\section{Quadro 5 - Detalhamento das etapas de aplicação do método do TP no contexto da construção}

\begin{tabular}{|c|c|c|}
\hline Etapa do método & $\begin{array}{l}\text { Documento e } \\
\text { Ferramentas }\end{array}$ & Comentários \\
\hline 1-Escolher serviço & - & $\begin{array}{l}\text { Para escolher o serviço em que será aplicado o método, é indicado } \\
\text { escolher serviços repetitivos, que tenham estabilidade básica dos 4Ms: } \\
\text { mão de obra, materiais, máquinas e método. Quanto maior a } \\
\text { abrangência do número de atividades e operadores estudados, maiores } \\
\text { serão os potenciais de combinações e decorrentes melhorias. }\end{array}$ \\
\hline $\begin{array}{l}\text { 2-Definir o tempo } \\
\text { takt }\end{array}$ & - & $\begin{array}{l}\text { O tempo takt é extraído do cronograma de execução da obra adotado } \\
\text { pela construtora. A fórmula é: } \\
\text { Tempo takt }=\text { tempo disponível/demanda do cliente }\end{array}$ \\
\hline $\begin{array}{l}\text { 3-Coletar atividades } \\
\text { fora do ciclo } \\
\text { repetitivo e tentar } \\
\text { eliminá-las }\end{array}$ & $\begin{array}{l}\text { Folha de Estudo de } \\
\text { Processo para o } \\
\text { turno e Gráfico de } \\
\text { Balanceamento do } \\
\text { Operador para o } \\
\text { turno }\end{array}$ & $\begin{array}{l}\text { Nesta etapa coletam-se dados das atividades realizadas em um dia de } \\
\text { trabalho do funcionário (medindo-se durante um ou mais dias, } \\
\text { dependendo da variabilidade das tarefas desempenhadas em um dia), } \\
\text { com o intuito de conhecer os desperdícios que ocorrem diariamente } \\
\text { entre os ciclos repetitivos. Dessa forma, podem ser discutidas } \\
\text { contramedidas para mitigar ou eliminar esses desperdícios. A folha de } \\
\text { estudo de processos para o turno é o documento para a coleta das } \\
\text { atividades e seu tempo; já o GBO para o turno é o gráfico que serve } \\
\text { para se fazer a análise de distribuição. }\end{array}$ \\
\hline $\begin{array}{l}\text { 4-Coletar elementos } \\
\text { de trabalho do ciclo } \\
\text { e definir o tempo } \\
\text { real para executá-los } \\
\text { (eliminar atividades } \\
\text { que não agregam } \\
\text { valor) }\end{array}$ & $\begin{array}{l}\text { Folha de Estudo de } \\
\text { Processo e Gráfico } \\
\text { de Balanceamento } \\
\text { do Operador }\end{array}$ & $\begin{array}{l}\text { Nesta etapa aprofunda-se a análise para conhecer os desperdícios que } \\
\text { estão no ciclo de execução do funcionário. A FEP serve para coletar } \\
\text { os elementos de trabalho, e o GBO, para fazer a análise em relação ao } \\
\text { tempo takt. }\end{array}$ \\
\hline $\begin{array}{l}\text { 5-Verificar se o } \\
\text { equipamento pode } \\
\text { operar de acordo } \\
\text { com o tempo takt e } \\
\text { ajustá-lo se } \\
\text { necessário }\end{array}$ & $\begin{array}{l}\text { Folha de Capacidade } \\
\text { de Produção e } \\
\text { Gráfico de } \\
\text { Balanceamento de } \\
\text { Máquinas }\end{array}$ & $\begin{array}{l}\text { Alguns serviços talvez não precisem passar por essa etapa, caso não } \\
\text { usem máquinas. } \\
\text { Caso utilizem máquinas, deve-se verificar se elas podem operar de } \\
\text { acordo com o takt. A folha de capacidade de produção mostra o } \\
\text { tempo total em que um ciclo do produto é produzido. Desse modo, } \\
\text { pode ser comparado com o takt para verificar se a máquina tem ou } \\
\text { não capacidade de atender. O gráfico de balanceamento de máquinas é } \\
\text { ilustrativo e compara todas as máquinas usadas no serviço em relação } \\
\text { ao tempo takt. }\end{array}$ \\
\hline $\begin{array}{l}\text { 6-Organizar leiaute } \\
\text { de trabalho }\end{array}$ & $\begin{array}{l}\text { Diagrama de } \\
\text { espaguete }\end{array}$ & $\begin{array}{l}\text { Nesta etapa evidenciam-se os desperdícios ocorridos com } \\
\text { deslocamento e transporte. Há uma maior discussão em relação a } \\
\text { logística interna do serviço. O diagrama de espaguete ilustra o } \\
\text { deslocamento do trabalhador no local de trabalho. Por meio desta } \\
\text { discussão são apresentadas contramedidas para atenuar esses } \\
\text { desperdícios, registradas num leiaute futuro. }\end{array}$ \\
\hline $\begin{array}{l}\text { 7-Calcular quantos } \\
\text { funcionários são } \\
\text { necessários }\end{array}$ & & $\begin{array}{l}\text { Nesta etapa utiliza-se a fórmula abaixo para se calcular a quantidade } \\
\text { necessária de operadores: } \\
\mathrm{N}^{\circ} \text { de operários = Soma dos elementos de trabalho/tempo de ciclo } \\
\text { planejado, sendo tempo de ciclo planejado }=80 \% \text { do tempo takt. } \\
\text { Algumas vezes nesta etapa é feita uma proposta de GBO futuro com } \\
\text { base no número ideal de funcionários. }\end{array}$ \\
\hline $\begin{array}{l}\text { 8-Distribuir o } \\
\text { trabalho entre os } \\
\text { funcionários }\end{array}$ & $\begin{array}{l}\text { Diagrama de } \\
\text { trabalho padronizado } \\
\text { e Tabela de } \\
\text { combinação do } \\
\text { trabalho padronizado }\end{array}$ & $\begin{array}{l}\text { Nesta etapa o trabalhado é distribuído entre os funcionários. A tabela } \\
\text { de combinação de trabalho padronizado mostra como as atividades } \\
\text { devem ser realizadas ao mesmo tempo entre funcionários diferentes } \\
\text { ou entre funcionários e máquinas. A TCTP também poderia ilustrar } \\
\text { tarefas realizadas por funcionários que executam elemento de trabalho } \\
\text { dentro do ciclo e atividades fora do ciclo para combinar esses } \\
\text { trabalhos. O diagrama de trabalho padronizado ilustra através de um } \\
\text { leiaute de trabalho o passo a passo que deve ser executado. }\end{array}$ \\
\hline 9-Implementar & & $\begin{array}{l}\text { Comunicar, treinar, implantar todas as decisões definidas nas etapas } \\
\text { anteriores. }\end{array}$ \\
\hline $\begin{array}{l}\text { 10-Manter e } \\
\text { melhorar }\end{array}$ & & $\begin{array}{l}\text { Auditar, fazer a solução de problemas e implantar a melhoria } \\
\text { contínua. }\end{array}$ \\
\hline
\end{tabular}


A aplicação deste método, como padronização de ciclos que se repetem com mínima variação, como na manufatura, não é possível em diversas situações na construção, como no exemplo do Caso 1 (assentamento de porcelanato), no que se refere a cantos, recortes, variações de dimensões em cômodos, etc., sendo esta uma limitação do método proposto. Entretanto, sua aplicação direciona melhorias mediante uma análise estruturada, que possibilita a identificação de desperdícios e orienta o planejamento de redução deles, pelo estabelecimento de um trabalho padronizado que otimiza os recursos utilizados, organizando leiaute, operadores, equipamentos, etc. Estudos posteriores podem combinar a análise micro, no nível dos movimentos do operador, propiciada por este método, com formas de comunicar e controlar a execução de ciclos repetitivos em unidades maiores, como cômodo, apartamento ou pavimento, adaptando o conceito de pitch (um múltiplo do tempo takt, conforme o Lean Institute Brasil, 2003).

A avaliação dos reais ganhos dependerá de estudos futuros, em que o TP gerado seja aplicado e seus resultados medidos. Além de possíveis ganhos de produtividade, a aplicação do TP tem potencial de trazer também benefícios em segurança, qualidade e estabilidade, não discutidos neste trabalho.

A proposta apresentada não tem a pretensão de estar acabada. Espera-se que a sistematização de análise por ela representada, orientando otimizações estruturadas, encoraje pesquisadores e profissionais do setor a aplicar o método em diferentes situações, relatando seus resultados e aperfeiçoamentos.

\section{Referências}

ALUKAL, G.; MANOS, A. Lean Kaizen: a simplified approach to process improvements. Milwaukee: Quality Press, 2006.

BULHÕES, I. R. Diretrizes Para Implementação de Fluxo Contínuo na Construção Civil: uma abordagem baseada na Mentalidade Enxuta. 2009. 339 f. Tese (Doutorado em Engenharia Civil) Faculdade de Engenharia Civil, Arquitetura e Urbanismo, Universidade Estadual de Campinas, Campinas, 2009.

BULHÕES; I. R.; PICCHI, F. A. Diretrizes Para a Implementação de Fluxo Contínuo em Obras de Edificações. Ambiente Construído, Porto Alegre, v. 11, n. 4, p. 205-223, out./dez. 2011.
CUDNEY, E. Using Standard Work in Lean Manufacturing. In: INSTITUTE OF INDUSTRIAL ENGINEERS INTERNATIONAL CONFERENCE, 51., Dallas, 2001. Proceedings... Dallas, 2001.

FAZINGA, W. R.; SAFFARO, F. A. Identificação dos Elementos do Trabalho Padronizado na Construção Civil. Ambiente Construído, Porto Alegre, v. 12, n. 3, p. 27-44, jul./set. 2012.

FENG, P.; BALLARD, G. Standard Work From a Lean Theory Perspective. In: ANNUAL CONFERENCE OF THE INTERNATIONAL GROUP FOR LEAN CONSTRUCTION, 16., Manchester, 2008. Proceedings... Manchester, 2008.

FRANCELINO, T. R. et al. Melhorias de Processos Com a Aplicação da Filosofia lean. In: ENCONTRO NACIONAL DE ENGENHARIA DE PRODUÇÃO, 26., Foz do Fortaleza, 2006. Anais... Fortaleza: ABEPRO, 2006.

FUJIMOTO, T. The Evolution of a Manufacturing System at Toyota. New York: Oxford University Press, 1999.

GALLARDO, C. A. S. Princípios e Ferramentas do Lean Thinking na Estabilização Básica: diretrizes para implantação no processo de fabricação de telhas de concreto pré-fabricadas. 2007. 118 f. Dissertação (Mestrado em Engenharia Civil) - Faculdade de Engenharia Civil, Arquitetura e Urbanismo, Universidade Estadual de Campinas, Campinas, 2007.

HUNTZINGE, J. The Roots of Lean. Lean Enterprise Institute, 2005. Disponível em: <http://www.leaninstituut.nl/publications/Roots_of _Lean_TWI.pdf>. Acesso em: 26 ago. 2013.

KISHIDA, M.; SILVA, A.; GUERRA, E. Benefícios da Implementação do Trabalho Padronizado na Thyssenkrupp. Lean Institute Brasil, 2006. Disponível em: <http://www.lean.org.br/artigos/95/beneficios-daimplementacao-do-trabalho-padronizado-nathyssenkrupp.aspx>. Acesso em: 26 ago. 2013.

LEAN INSTITUTE BRASIL. Léxico Lean: glossário ilustrado para praticantes do pensamento lean. Tradução de Lean Institute Brasil. São Paulo: Lean Institute Brasil, 2003.

LIKER, J. K.; MEIER, D. O Modelo Toyota: manual de aplicação. Porto Alegre: Bookman, 2007.

LUYSTER, T. Creating Your Lean Future State: how to move from seeing to doing. New York: Quality Press, 2006. 
MARKSBERRY, P.; RAMMOHAN, R.; VU, D. A Systems Study on Standardized Work: a Toyota perspective. International Journal of Productivity and Quality Management, v. 7, n. 3, p. 287-302, 2011.

MONDEN, Y. Toyota Production System: an integrated approach to just in time. 3. ed. Norcross: Engineering and Pressure, 1998.

NARUSAWA, T.; SHOOK, J. Kaizen Express: fundamentos para sua jornada lean. Tradução de Lean Institute Brasil. São Paulo: Lean Institute Brasil, 2009.

OHNO, T. O Sistema Toyota de Produção: além da produção em larga escala. Porto Alegre: Bookman, 1997.

PICCHI, F. A. Oportunidades da Aplicação do Lean Thinking na Construção. Revista Ambiente Construído, Porto Alegre, v. 3, n. 1, p. 7-23, jan./mar. 2003.

ROTHER, M.; HARRIS, R. Criando Fluxo Contínuo: um guia de ação para gerentes, engenheiros e associados da produção. São Paulo: Lean Institute Brasil, 2002.

SAFFARO, A. F. Uso da Prototipagem Para Gestão do Processo de Produção da Construção civil. 2007. 237 p. Tese (Doutorado em Engenharia Civil) - Programa de Pós-Graduação em Engenharia Civil, Universidade Federal de Santa Catarina, Florianópolis, 2007.

SANTOS, A. Application of Flow Principles in the Production Management of Construction Sites. 1999. 513 f. Thesis (Ph.D.) - School of Construction and Property Management, The University of Salford, Manchester, 1999.
SHOOK, J. Bringing the Toyota Production System to the United States: a personal perspective. In: LYKER, J. K. (Ed.). Becoming Lean: inside stories of U.S. manufactures. Portland, OR: Productivity Press, 1997.

SMALLEY, A. The Starting Point For Lean Manufacturing: achieving basic stability. Management Services, v. 49, n. 4, p. 8-12, 2005.

SOUZA, D. P. et al. Uma Metodologia de Implantação do Sistema Toyota de Produção em Uma Empresa de Construção de Edifícios a Partir do Suporte Tecnológico do Programa de Inovação da Construção Civil do Ceará (INOVACON-CE). In: SIMPÓSIO BRASILEIRO DE GESTÃO E ECONOMIA DA CONSTRUÇÃO, 4., Porto Alegre, 2005. Porto Alegre. Anais... Porto Alegre: ANTAC, 2005.

SPEAR, S.; BOWEN, H. K. Decoding the DNA of the Toyota Production System. Harvard Business Review, Boston, v. 77, n. 8, p. 96-106, 1999.

THOMAS, H.R. Effects of scheduled labor productivity. Journal of Construction Engineering Management, v. 118, n. 1, p. 60-76, 1992.

WHITHMORE, T. Standardized Work: document your process and make problems visible.

Manufacturing Engineering, v. 140, n. 5, 2008.

WOMACK, J. P.; JONES K. T. A Mentalidade Enxuta nas Empresas: elimine os desperdícios e crie riqueza. 5. ed. Rio de Janeiro: Campus, 1998.

\section{Agradecimentos}

Ao $\mathrm{CNPq}$, pela bolsa de mestrado ao primeiro autor, e ao Lagercon (Laboratório de Gerenciamento da Construção).

\section{Renato Nunes Mariz}

Faculdade de Engenharia Civil, Universidade Estadual de Campinas | Avenida Albert Einstein ,951 | Campinas - SP Brasil | Tel.: (19) 35212314 |E-mail: renatonunesmariz@hotmail.com

Flávio Augusto Picchi

Laboratório de Gerenciamento em Construção, Faculdade de Engenharia Civil, Universidade Estadual de Campinas / Lean Institute Brasil | Rua Brás Cubas, 187, Aclimação| São Paulo - SP - Brasil | CEP 04105-063 | Tel.: (11) 5571-0804 | E-mail: fpicchi@lean.org.br

Revista Ambiente Construído

Associação Nacional de Tecnologia do Ambiente Construído

Av. Osvaldo Aranha, $99-3^{\circ}$ andar, Centro

Porto Alegre - RS - Brasil CEP 90035-190

Telefone: +55 (51) 3308-4084

Fax: +55 (51) 3308-4054

www.seer.ufrgs.br/ambienteconstruido

E-mail: ambienteconstruido@ufrgs.br 